\title{
REFERENCE
}

NITED STATES DARTMENT OF DMMERCE IBLICATION

\section{unt of $\mathrm{ca}$ \\ (4) of \\ II. 15

\section{BUILDING}

\section{RESEARCH TRANSLATION}

\section{Use of an}

Air-to-Air Heat Exchanger

To Recover Heat from Air

Exhausted by Mechanical

Ventilation

U.S.

ARTMENT

OF OMMERCE

QC 100 45753 no. 710.5 1972 
The National Bureau of Standards ${ }^{1}$ was established by an act of Congress March 3, 1901. The Bureau's overall goal is to strengthen and advance the Nation's science and technology and facilitate their effective application for public benefit. To this end, the Bureau conducts research and provides: (1) a basis for the Nation's physical measurement system, (2) scientific and technological services for industry and government, (3) a technical basis for equity in trade, and (4) technical services to promote public safety. The Bureau consists of the Institute for Basic Standards, the Institute for Materials Research, the Institute for Applied Technology, the Center for Computer Sciences and Technology, and the Office for Information Programs.

THE INSTITUTE FOR BASIC STANDARDS provides the central basis within the United States of a complete and consistent system of physical measurement; coordinates that system with measurement systems of other nations; and furnishes essential services leading to accurate and uniform physical measurements throughout the Nation's scientific community, industry, and commerce. The Institute consists of a Center for Radiation Research, an Office of Measurement Services and the following divisions:

Applied Mathematics-Electricity-Heat-Mechanics-Optical Physics-Linac Radiation ${ }^{2}$ - Nuclear Radiation ${ }^{2}$ - Applied Radiation ${ }^{2}$-Quantum Electronics ${ }^{3}-$ Electromagnetics ${ }^{3}$ - Time and Frequency ${ }^{3}$ - Laboratory Astrophysics ${ }^{3}$-Cryogenics $^{3}$.

THE INSTITUTE FOR MATERIALS RESEARCH conducts materials research leading to improved methods of measurement, standards, and data on the properties of well-characterized materials needed by industry, commerce, educational institutions, and Government; provides advisory and research services to other Government agencies; and develops, produces, and distributes standard reference materials. The Institute consists of the Office of Standard Reference Materials and the following divisions:

Analytical Chemistry-Polymers-Metallurgy-Inorganic Materials-Reactor Radiation-Physical Chemistry.

THE INSTITUTE FOR APPLIED TECHNOLOGY provides technical services to promote the use of available technology and to facilitate technological innovation in industry and Government; cooperates with public and private organizations leading to the development of technological standards (including mandatory safety standards), codes and methods of test; and provides technical advice and services to Government agencies upon request. The Institute also monitors NBS engineering standards activities and provides liaison between NBS and national and international engineering standards bodies. The Institute consists of the following divisions and offices:

Engineering Standards Services-Weights and Measures-Invention and Innovation-Product Evaluation Technology-Building Research-Electronic Technology-Technical Analysis-Measurement Engineering-Office of Fire Programs.

THE CENTER FOR COMPUTER SCIENCES AND TECHNOLOGY conducts research and provides technical services designed to aid Government agencies in improving cost effectiveness in the conduct of their programs through the selection, acquisition, and effective utilization of automatic data processing equipment; and serves as the principal focus within the executive branch for the development of Federal standards for automatic data processing equipment, techniques, and computer languages. The Center consists of the following offices and divisions:

Information Processing Standards-Computer Information-Computer Services -Systems Development-Information Processing Technology.

THE OFFICE FOR INFORMATION PROGRAMS promotes optimum dissemination and accessibility of scientific information generated within NBS and other agencies of the Federal Government; promotes the development of the National Standard Reference Data System and a system of information analysis centers dealing with the broader aspects of the National Measurement System; provides appropriate services to ensure that the NBS staff has optimum accessibility to the scientific information of the world, and directs the public information activities of the Bureau. The Office consists of the following organizational units:

Office of Standard Reference Data-Office of Technical Information and Publications-Library-Office of International Relations.

\footnotetext{
${ }^{1}$ Headquarters and Laboratories at Gaithersburg, Maryland, unless otherwise noted; mailing address Washington, D.C. 20234 .

2 Part of the Center for Radiation Research.

s Located at Boulder, Colorado 80302 .
} 


\section{BUILDING RESEARCH TRANSLATION \\ Use of an Air-to-Air Heat Exchanger To Recover Heat from Air Exhausted by Mechanical Ventilation}

P. Garrivier

Centre Scientifique et Technique du Bâtiment

Paris, France

Translated by the Joint Publication

Research Service,

U.S. Department of Commerce,

Washington, D.C. 20234

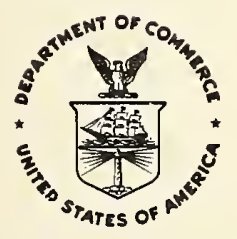

U.S. DEPARTMENT OF COMMERCE, Peter G. Peterson, Secretory

U..S. NATIONAL BUREAU OF STANDARDS, Lawrence M. Kushner, Acting Direcfor,

Issued July 1972 


\section{National Bureau of Standards Technical Note 710-5}

Nat. Bur. Stand. (U.S.), Tech. Note 710.5, 62 pages (July 1972)

CODEN: NBTNAE

For sule by the Superintendent of Docurnents, U.S. Government Printing Office, Washington, D.C. 20402 (Order by SD Catalog No. C13.46:710-5). Price 60cents. 


\section{FOREWORD}

The United States/French Cooperative Program on Building Technology entails an exchange of personnel between the National Bureau of Standards (Building Research Division) and the Centre Scientifique et Technique du Bâtiment (CSTB) of France. The program also involves the exchange of information between the two research organizations.

It is felt that some of the documented information can be usefully shared with the U.S. building industry; and, therefore, certain papers were selected for reproduction in media on sale to the public by the Government Printing office. It should be understood that the CSTB documents made public through such media as this TECHNICAL NOTE do not necessarily represent the views of the National Bureau of Standards on either policy or technical levels.

At the same time, building researchers at the National Bureau of Standards consider it a public service to share with the U.S. building industry certain insights into French building technology.

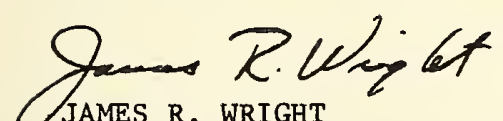

JAMES R. WRIGHT

Chief, Building Research Division

Institute for Applied Technology

National Bureau of Standards 

BUILDING RESEARCH TRANSLATION

USE OF AN AIR-TO-AIR HEAT EXCHANGER

TO RECOVER HEAT FROM AIR EXHAUSTED

BY MECHANICAL VENTILATION I/

by

P. Garrivier, Engineer

When a building is equipped with a mechanical system which both exhausts and supplies outdoor air, it may be profitable to install a heat exchanger between the two circuits. The CSTB has perfected such an exchanger, which meets the two principal requirements of the problem: good efficiencies and elimination of the polluted air intake. A method of calculating the optimal dimensions of the exchanger has also been devised.

Key words: Exchanger dimensions; frost formation; heat exchanger; heating costs; mechanical systems; pollution; pressure loss; ventilation.

I/This paper is translated from the French original and is published under the Building Research Division, Centre Scientifique et Technique du Bâtiment information exchange program. 


\section{INTRODUCTION: FEASIBILITY OF EXCHANGER LINKED TO DEVELOPMENT OF MECHANICAL VENTILATION.}

Heat loss through air change represents, in general, some 30 per cent of the overall heat loss in a multiple-dwelling building and approximately 20 per cent of such loss in a single house.

Recovery of heat from the outgoing air by means of a heat exchanger installed between the exhaust air and the incoming air can therefore achieve significant savings. With an exchanger efficiency of 70 per cent--the actual efficiency attained by the CSTB-developed exchanger--the resultant saving in heating is of the order of 21 per cent ( $0.30 \times 0.70)$ in a multiple-occupancy building, and 14 per cent $(0.20 \times 0.70)$ in a single house.

With the improved insulation of walls, floors and ceilings and the increased demands for air purity, these figures should increase appreciably in years to come.

The cost of the exchanger per se--as we shall see later--is not high. But its utilization does assume that the building is equipped with a mechanical forced (blown) air intake and a mechanical exhaust. Use of the latter is expanding rapidly in France. In 1971, 15 to 20 per cent of the residential construction will have such equipment. In 10 years the figure will perhaps be 30 to 40 percent, with the figure in multipledwelling buildings probably rising to over 50 per cent. On the other hand, the forced air-delivery system, i.e. by means of a mechanical ventilation, is currently nonexistent, so to speak. The reason for this is its high cost, which is not the case of mechanical extraction or exhaust equipment. 
In fact, exhausting air by natural circulation (draft) requires vertical ducts or conduits, which in a multiple-dwelling building cost nearly as much as a mechanical exhaust system. On the other hand, the delivery of air is generally accomplished by means of simple openings on the outside walls. Their cost is much lower than that of a mechanical forced-air delivery system. We do believe, however, that mechanical forced-air delivery will experience some expansion in the coming years for the following reasons:

1. A first reason is the need to shield oneself against noise in areas such as those close to airports, superhighways, and other roads and highways. To do this one must satisfy air-purity and thermal-comfort requirements without opening any windows. Thus a mechanical forced-air supply is almost indispensable, first, in order to eliminate ventilation openings in outside walls, then to obtain greater flexibility in heating (that is so as not to be obliged to control heating by opening windows), and lastly, to obtain the large number of necessary air changes in the summertime (which are usually obtained by opening windows).

2. A second reason is the requirement to humidify the air in cold dry weather. This need will become increasingly greater because, first of all, comfort demands are growing, and then because the higher temperatures desired by occupants lower relative humidity, and lastly because while good ventilation (i.e. mechanical exhaust in kitchens, bathrooms, toilets) does eliminate odors, it also lowers the humidity in the main rooms (kitchen, bathroom, etc.)

The calculations found in the appendix to this document, show that during an average winter in Paris and within a room heated to $21^{\circ} \mathrm{C}$ in a 
properly ventilated dwelling, air humidity is below 20 per cent during eight days and ranges from 20 to 25 per cent for 16 days, from 25 to 30 per cent for 28 days, and from 30 to 35 percent for 30 days.

If 35 per cent is deemed to be the minimum desirable humidity, then the air must be humidified during 94 days, and within the room under consideration the following amounts of water must be evaporated daily: 1.6 liters when humidity is 20 per cent, 1.1 liters when it is 25 per cent, and 0.5 liter when it is 30 per cent.

The number of days in which humidification is necessary and the quantitities of water that must be evaporated, are both considerable. It is difficult to do this properly without having air mechanically introduced into the dwelling.

3. A third reason is the desirability of filtering the air, a requirement that will grow as pollution increases.

4. A fourth reason is the need to control ventilation in very windy sites, e.g. in high-rise buildings, so as to avoid disagreeable drafts and recurrent temporary drops of the indoor temperature.

5. A fifth reason is the attempt to find an exceptionally flexible means of heating, at least of secondary or supplementary heating.

Several of these reasons take on increased importance when electric heating is involved. In fact a higher degree of comfort has to be provided to warrant what is generally a highly expensive proposition. Furthermore, to limit this expenditure one must have control over all heat loss through air changes. And lastly, because of the advances in wall, ceiling, and floor insulation, any heat loss through air changes is relatively greater, hence the added value of the exchanger and 
consequently of a forced air intake. Up to now we have talked only about the residential aspects of this question. But in other areas of activity the development of forced-air systems may be more rapid: in hospitals for comfort and hygienic reason; in schools--frequently lacking thermal inertia and very densely occupied--for reasons of thermal comfort in the summer and also for reasons of flexibility in heating; and in offices that are being air-conditioned with increasing frequency and where, as a result, a forced-air intake is available almost automatically.

And finally, we wish to add that the heat exchanger may in certain types of construction, or with certain types of equipment, be used for summer comfort, with or without air conditioning. But this subject is still under study and we shall not elaborate on it in this document.

2. VARIOUS HEAT-RECOVERY SYSTEMS DESERVING CONSIDERATION: SYSTEMS CURRENTLY AVAILABLE FOR DWELLING USE.

We shall survey existing exchanger systems by examining advantages and disadvantages of each one from various points of view, particularly:

--that of efficiency which is obviously of capital importance;

--that of pressure loss which increases ventilation costs and makes acoustic problems more difficult to resolve;

--that of frost formation which affects efficiency;

--that of sanitation: the forced-air intake must not be polluted by the exhausted air. 


\subsection{Solutions Based on the Thermal Inertia of a Material.}

There are many such solutions. They may involve having the incoming air and the outgoing air alternately pass over a divided mass so that the warm stream yields its heat to the mass and the cold stream is warmed upon contact with that mass. Different arrangements are possible. For example, one apparatus consists of two chambers containing the material and through which each stream passes for a certain period of time with periodic reversal (such solutions are utilized industrially, especially in the iron and steel industry).

The efficiency, small pressure-loss, and relatively meager space requirement of these solutions, are all advantages. But the solutions do have the disadvantage of recirculating odors and impurities as the new air passes over the material polluted by the exhausted air. Moreover, recirculation of a certain volume of gas occurs at the moment of aircurrent inversion or reversal. This disadvantage can be limited by purging the exchanger at the moment of reversal, but this requires additional apparatus. In addition, the exchange mass of material may gradually become fouled and clogged. This situation can be remedied by either the use of a washing device or by simply replacing the material, both solutions which do have their disadvantages. Figure 1 has an illustrative diagram.

Another application of this same principle is the rotary-exchanger solution. It consists of a porous wheel which rotates about an axis paralled to two gaseous streams separated by a wall that diametrically intersects the wheel (see Figure 2). In this solution, the air streams 
follow a fixed course and it is the collector (accumulating) material that passes from one stream to the other at variable speed. This solution which, under good conditions, is capable of achieving 80 per cent efficiency, has the same disadvantages as the previous solution. A purger permits limiting the recirculation of stale air at the point where the wheel crosses the boundary between the stream of exhausted air and the stream of new air. But there is still a risk of recirculation on a level with the joint or seal between the rotating part and the barrier separating the two streams. This risk may be limited if the pressure of the new air exceeds that of the exhausted air (which is generally the case).

These exchangers are widely used in the Scandinavian countries (a Swedish firm makes them), and in North America (there is a Canadian manufacturer). A study by the National Research Council of Canada's Division of Building Research revealed that even in the best of cases there was still a two to four per cent recirculation of the bacteria contained in the exhausted air. This situation indicates that highefficiency filters should be added to the system. Moreover, the fouling and clogging of the air passages that pass through the wheel (with a resultant increase in pressure loss through the wheel plus transmission of odors) can be prevented only by prior filtering of the exhausted air (this is an important constraint). In practice this solution is not used in kitchens, a fact that greatly reduces its value.

Frost is apt to form within these types of exchangers when the moist outgoing air passes over that part of the exchange material whose tempereture is close to the outside temperature which is below $0^{\circ} \mathrm{C}$. This 
condition can be corrected by use of a preheating system or by shunting the system below a certain outside temperature. Unfortunately these remedial steps decrease exchanger efficiency.

\subsection{Systems Employing an Intermediary Heat-Carrying Fluid.}

This solution consists in having a heat-carrying fluid circulate between two finned tube coils, one set within the warm-air stream, the other within the cold air stream. A pump serves to circulate this fluid. (See Figure 3.)

This system offers significant advantages over the previous one:

--the exhaust ducts and forced-air intake ducts in which heat exchange occurs may be placed at some distance from each other,

--recirculation of odors and contaminants is impossible.

On the other hand, this solution is not very economical. Initial investment costs are high and the conventional finned tube coils cause considerable pressure loss whenever they are required to work effectively.

Frost problems and fouling difficulties are resolved as in the first solution.

\subsection{Systems Using Direct Heat Transfer Through a Conductive Wall Surface.}

This is the family of "plate" heat exchangers. They exist in various forms and with counterflow, parallel flow, crossflow... There are manifold versions of these exchangers, mainly with applications rather different and remote from those being considered here (we are aware of no applications of this type of exchanger in the building field). 
One variation consists in having the exhaust and forced-air intake ducts arranged coaxially so that transfer occurs throughout the building's height, with the gases flowing in opposite directions, counterflow. We did not consider this version worthy of more detailed study.

\section{DEVELOPMENT OF A PROTOTYPE}

\subsection{Choices}

\section{Selection of the Type of Exchanger}

This survey of the different types of heat exchangers revealed that:

--exchanger employing the inertia of a material can have a high degree of effectiveness but have disadvantages from the hygienic and odor point of view;

--exchanger with an intermediary heat-transporting fluid are not = economically satisfactory in our application.

That leaves the plate-type exchangers whose efficiency and economy depend essentially upon the nature and geometry of the plates. We decided to especially study this last solution in greater detail.

\section{Selection of a Configuration}

There are three basic configurations open to consideration:

- counterflow:

- parallel Flow:

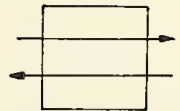

- crossflow:

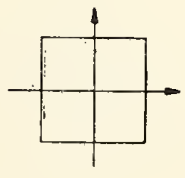


There are other solutions that combine these three single solutions. For reasons of manufacturing simplicity we did not retain them for further consideration.

The parallel-flow exchanger is not conducive to an acceptable efficiency (for example, in the case of two identical flow rates, efficiency is limited to 50 per cent).

The crossflow exchangers when compared with the counterflow exchanger has the advantage of an easy arrangement of apertures, with solely one gaseous flow issuing onto each surface. This is a solution frequently adopted for gas-to-gas exchangers. We chose this solution as the one to use in building a research model.

Note: from results obtained with this model, it was subsequently possible to deduce those results obtained in different configurations with plates having the same characteristics.

Selection of a Material

Factors that must be considered:

--cost of the material,

--its ease of employment, especially the ease with which it can be formed or molded,

--its mechanical behavior in the planned field of utilization,

--its chemical behavior,

-its conductivity.

It should be noted that if small thicknesses of material are used to make the plates, then the last factor is only of secondary importance: the thermal resistances encountered are mainly those of heat transfers by convection between air and plates. 
The cost of the material and its durability must be considered together:

--either the material used is expensive (per se or in its application) and designed to last several years without deterioration,

--or else an inexpensive material is selected and it is conceded that the part of the exchanger consisting of the pile of plates will be replaced at rather close time intervals (every year, for example).

It must be noted that in the case of the "long-lasting" plates, the exchanger cleaning problem has to be resolved. If filters are not installed, then a capability must be provided for periodically cleaning of the entire plate assembly. This cleaning operation must be taken into account when determining the economic feasibility of such plates, and moreover, it imposes certain constraints in the manufacture of the exchanger. By changing the plates, e. g. annually, such constraints and cleaning operations are avoided.

Consequently, the "expendable" plates solution was the one chosen. We directed our effort toward finding a very inexpensive material that was also simple to produce commercially, namely a plastic material that could be "hot-formed" or molded. Tests were conducted on small-size samples to determine their plasticity (capability to be shaped or molded), and their mechanical behavior when not very thick. These tests led us to choose--not exclusively--0.17 mm-thick sheets of cellulose acetate. (This product is available commercially under the trade name of Rhodialine. It has a density of $1.29 \times 10^{3} \mathrm{~kg} / \mathrm{m}^{3}$ and a maximum utlization temperature of $60^{\circ} \mathrm{C}$. ) 
The following requirements had to be taken into account:

--plates had to be easily obtainable by a "hot-forming" process and fabrication of the mold must not be too complex;

--there must be maximum convection but all pressure loss or drop nevertheless had to be quite low;

--plates had to be "self-supporting," in other words the use of braces or ties must not be required to join these plates together, and they must be capable of being piled or stacked naturally.

We adopted a geometry reminiscent of an egg carton. It was obtained by the simultaneous and opposing compression of two matrixes having identical networks (grids) of studs with both networks being staggered a half module (the patent statement annexed hereto gives a more detailed description of this type of surface).

\subsection{Building of the Prototype}

The model exchanger was fabricated in the CSTB, using a variety of in-house equipment and machine tools. The limitations of these tools and equipment did impose the dimensions adopted for the plates. These dimensions were, however, of a highly suitable order of magnitude as subsequently demonstrated by the study of optimum exchanger dimensions.

\section{Fabrication of a Matrix}

Use of the CSTB's available "hot-forming" equipment necessitated separate casting of each plate. In large-scale industrial production this process would be advantageously replaced by a continuous calendering of the plates. 
The matrix was made in several stages:

1. Fabrication of a model shaped like the plates. To accomplish this, 931 cylindrical plexiglass studs or pins, $10 \mathrm{~mm}$ in diameter and $8 \mathrm{~mm}$ high, were glued to a wooden base (19 mm lathing) in a $30 \mathrm{~mm}$-module grid pattern. A 3 mm-thick sheet of butyl rubber was spread over the studs, and then with the help of a template, a tack was nailed into the center of each square formed by four adjacent studs, these fastening the butyl rubber down against the wood at that point (see Figure 5).

2. A matrix was then cast upon this form. A metal (U-bar) frame was placed along the perimeter of the model (see Figure 6) and a $40 \mathrm{~kg}$ mixture of polyester resin and aluminosilicate with a polymerizing agent and accelerator, were poured inside the metal frame. One hour later polymerization was complete and the polyester matrix could then be separated from the form.

3. To make the matrix suitable for use on CSTB equipment, it was then necessary to pierce a small-diameter hole in the bottom of each concave part of the matrix (this hole allows a reduced pressure to be created in each of the small cavities of the matrix during "hot-forming").

\section{Hot-Forming of the Plates}

This operation was carried out on the CSTB's "Illig" hot-forming machine. Matrix dimensions had been selected so that available equipment could be used (see Figure 7).

The operation consisted of the following successive steps:

--infrared heating at $110^{\circ} \mathrm{C}$ (on movable carriage);

--slight distention of the sheet to be formed;

--suction from under the matrix, 
--cooling period.

Plates were then cut into 915 by $915 \mathrm{~mm}$ square units.

\section{Assembling the Plates}

The useful part of the prototype exchanger consists of a pile of 22 plates. These were arranged in this pile by means of four corner guides positioned perpendicular to the plates. These guides are $40 \mathrm{~mm}$ X $40 \mathrm{~mm}$ sa. cross sections matching the small areas cut out at the corners of each plate. Two successive plates were symmetrical with reference to the plane containing their points of contact, points which are the high points ("summits") of the surface. Some of these points were roughly glued to each other.

The parallel edges of successive sheets were glued together in pairs, the first in one direction, the second in another, so as to enable gaseous streams to flow from one layer to another in perpendicular directions.

A rubber "leading edge" was mounted on the adhesive-bonded edges to provide a better mechanical hold and a good seal. This precautionary step could be dispensed with in large-scale production where suitable binding equipment would be used.

After the plates had thus been assembled, the unit was set into a frame or case which provided rigidity to the entire assembly. This case could be easily removed: a threaded stem or bolt mounted on each corner guide permitted tightening the frame with a wing nut. The top and bottom plates were insulated from the frame by a $3 \mathrm{~cm}$-thick sheet of expanded polystyrene. 
A foam-rubber seam served to seal the corners where plates and bracing guides joined.

Figures 8 and 9 depict this assembly method.

Exchanger Connections

The parallelepiped formed by the plates is finished off with sheetmetal sleeves connecting the circular cross sections of the ventilation ducts to the rectangular inlet cross sections of the exchanger (see Figure 10).

4. TESTS AND MEASUREMENTS ON THE PROTOTYPE BUILT AT THE CSTB

\subsection{Test Equipment (Figure 11)}

Testing facilities reproduced a central forced-air intake and exhaust system for a building or dwelling. It therefore included a forcedair intake circuit with its own fan and an exhaust circuit with its fan. Dampers were used to regulate the flow rate in each of the circuits.

Tests reproduced normal application conditions. An electric heater was installed in the exhaust circuit. Since its heat output could be continuously controlled, it was thus possible to reproduce inside conditions as desired.

Afterward a system for reproducing variable humidity conditions (greater than those of the outside air) was added to this air-heating system. This humidity system consisted of an insulated tank, equipped with a variable-power electric resistor. This device produced a known quantity of water vapor which was injected by suction into the exhaust circuit downstream from the electrical resistance heaters (see Figure 12). 
Since a condensation process might occur within the exchanger and cause liquid condensation to be formed in the cavities of the plates, the exchanger was positioned vertically with the exhaust air circulating through it from top to bottom (see Figure 13). Provisions were made to absorb and measure the condensates.

Initial tests were conducted under natural outside conditions, and the air was forced (blown) inside at outside temperature. Tests for frost formation required low outside temperatures. Therefore a refrigerating unit had to be attached to the forced-air intake circuit. But, then when these tests lasted several days, frost formed upon the refrigerating unit itself. To solve this problem the forced-air intake was made to circulate in a closed duct without any input of outside air (see Figure 14).

\subsection{Magnitudes Measured}

Flow rates: On each of the two circuits, flow rates were measured with the help of a diaphragm inserted within the rectilinear portions of the ducts.

Pressure losses: Pressure valves were mounted in both circuits on both sides of the plates. Continuous recording of pressure losses was possible.

Temperatures: Thermocouples placed at various points within the circuits were used to measure temperatures: they could be recorded on multichannel potentiometers.

Air temperatures were measured particularly at the following points: --on the outside,

--at the forced-air duct inlet, 
--at the exchanger inlet on the forced-air intake duct,

--at the exchanger inlet on the exhaust duct,

--downstream from the heating elements on the exhaust duct,

--at the exchanger oulets on both circuits, immediately

where both streams issue from the plates. Since temperatures

were not uniform at these points, thermocouples were mounted

on frames forming on integral part of the exchanger, each

frame carried nine thermocouples (see Figure 15),

--after mixing of the air streams, at the exchanger outlet

on both circuits.

\subsection{Test Results}

\subsection{Pressure Loss}

Measurements were made at various temperatures and for different rates of flow. Figure 16 shows average results observed.

Although pressure loss did rapidly reach a high value for the higher flow rates, it can be seen that for a prototype-exchanger flow rate of, for example, $350 \mathrm{~m}^{3} / \mathrm{h}$, the pressure loss was some 120 Pascal, which is not excessive.

Measurements were also taken of that pressure loss caused by partial obstruction of the inlet or the outlet of the plates, and also by a dual partial obstruction at both the inlet and outlet as depicted in Figure 17. Results of the measurements are plotted on Figure 16.

The advantages of such obturation are discussed in paragraph 4.34 .

\subsection{Efficiency}

The efficiency or effectiveness in question is solely that of the heat transfer from one gaseous stream to another. 


$$
\text { Where } \begin{aligned}
D_{i} & =\text { mass rate of flow of exhausted air, } \\
D_{e} & =\text { mass rate of flow of forced-air intake, } \\
t_{i} & =\text { pre-exchanger temperature of exhausted air, } \\
t_{i}^{\prime} & =\text { post-exchanger temperature of exhausted air, } \\
t_{e} & =\text { pre-exchanger temperature of forced-air intake, } \\
t_{e}^{\prime} & =\text { post-exchanger temperature of forced-air intake, }
\end{aligned}
$$

we can define efficiency by the equation:

$$
r=\frac{D_{e}\left(t_{e}^{\prime}-t_{e}\right)}{D_{i}\left(t_{i}-t_{e}\right)}
$$

For measurements, we must in principle observe the equality:

$$
\mathrm{D}_{i}\left(t_{i}-\mathrm{t}_{i}^{\prime}\right)=\mathrm{D}_{e}\left(t_{e}^{\prime}-t_{e}\right)
$$

In point of fact, that was not entirely the case. Actually, despite the insulation of ducts on both sides of the exchanger, a heat loss occurred in the distances covered between the plates and the point of measurement (temperature after mixing of air streams). The equality shown was not altogether verified. As a consequence the real efficiency is underestimated if equation $l$ is used. An estimate closer to the true thermal efficiency can be given by the equation:

$$
r^{\prime}=\frac{\mathrm{D}_{e}\left(t_{e}^{\prime}-t_{e}\right)}{\mathrm{D}_{e}\left(t^{\prime}{ }_{e}-t_{e}\right)+\mathrm{D}_{i}\left(t_{i}-t_{i}^{\prime}\right)}
$$

Efficiencies calculated with both equations, were $D_{i}$ and $D_{e}$ are equal, have been plotted on Figure 18 .

It appears that although $r$ and $r^{\prime}$ did differ appreciably at low flow rates, they were, on the other hand, practically equal at flow rates above $350 \mathrm{~m}^{3} / \mathrm{h}$.

Maximum efficiency was attained at flow rates of the order of $400 \mathrm{~m}^{3} / \mathrm{h}$, where it amounted to 70 per cent. 
The varying difference between $r$ and $r^{\prime}$ as a function of flow rate is explained by the fact that although stray (infiltration) heat losses increase as flow rate rises, they increase relatively less than the exchanger's own heat transfer.

The measured efficiencies did not vary appreciably with forced-air intake temperatures.

Measurements were made in the case of different $\mathrm{D}_{i}$ and $\mathrm{D}_{\mathrm{e}}$ flow rates, but these were not of considerable interest. In fact, when $D_{i}$ is lower than $D_{e}$, in other words when more air is forced (blown) in than is exhausted, efficiency will be greater than that obtained when $\mathrm{D}_{e}$ is equal to $\mathrm{D}_{i}$. It will even tend toward 1 when $\mathrm{D}_{i}$ is much lower than $\mathrm{D}_{e}$, but in that case the exchanger might be of limited advantage. In the opposite case, the efficiency is less than for two equal flow rates and tends toward zero if the difference in fllow rates is very pronounced.

\subsection{Increased Efficiency when there Is Condensation of the Water-Vapor} in the Exhausted Air.

During the second series of tests, the exhausted air was humidified by means of the apparatus described earlier.

Although the tests without humidification displayed a certain constancy of the results vis-à-vis outside conditions, the same is not true when--as may well be imagined--the following parameters are involved:

--exhausted air's moisture content,

--temperature of forced-air intake.

Only a limited number of tests were conducted because of the length of time required to get the humidifying equipment operating normally. These tests did reveal, however, that for exhausted-air relative humidity 
below 50 per cent and for outside temperatures higher than $-5^{\circ} \mathrm{C}$, results obtained did not differ appreciably from those observed in tests without humidification.

For higher inside humidity conditions, an improvement was noted in efficiency. Although limited, this improvement could be of three to four per cent in the extreme case of a 100 per cent relative humidity.

It cannot be said, therefore, that in such an exchanger there was a spectacular recovery of the "latent" heat corresponding to the water-vapor content of the exhausted air.

On the other hand, it must be noted that the average relative humidity encountered during the heating season in dwellings is not too high. And even if there is a humidifier for the forced-air intake, it would be economical to have that humidification accomplished at least possible cost, and thus have it correspond to the minimum compatible with comfort requirements. Moreover, it would be particularly illogical to employ in one and the same building a heat-recovery system and a humidifying system, in such a way as to generate waste.

NOTE: It may be asked whether the definition of efficiency used previously must still be accepted. The same equation may be used, but by replacing temperatures with enthalpies. This is tantamount to including within the amount of recoverable heat, that latent heat of vaporization corresponding to the difference between the water-vapor content of the exhausted air and the forced-air intake.

Calculation of "enthalpic" efficiency evidently leads to a result inferior to the one obtained with temperatures. This stems from the fact that condensation of the water vapor contained in the exhausted air occurs 
in only a limited part of the exchanger.

Let us consider an example that will be better understood by consulting the psychrometric chart in Figure 19. Let us assume that at the exchanger inlet the exhausted air is at $20^{\circ} \mathrm{C}$ and contains five grams of water vapor per kilogram of air (point 1 on the diagram); its relative humidity is thus 35 per cent and its enthalpy is $7.8 \mathrm{kcal} / \mathrm{kg}$. Let us assume that the forced-air intake is at $0^{\circ} \mathrm{C}$ and contains three grams of water vapor per kilogram of air (point 2 on the diagram); its relative humidity is thus 80 per cent and its enthalpy is $1.8 \mathrm{kcal} / \mathrm{kg}$.

Let us assume that the forced-air intake leaving the exchanger is $14^{\circ} \mathrm{C}$ and the exhausted air is $6^{\circ} \mathrm{C}$; as the weight of the vapor in the exhausted air has not changed--there can be no condensation for it, since it is being warmed--its vapor weight is still three grams per kilogram of $\operatorname{air}$ (point $2^{\prime}$ on the diagram) and its enthalpy is $5.2 \mathrm{kcal} / \mathrm{kg}$.

Therefore efficiencies are:

--in temperatures:

$$
r=\frac{t^{\prime}{ }_{e}-t_{e}}{t_{i}-t_{\theta}}=\frac{14-0}{20-0}=\frac{14}{20}=70 \%
$$

--in enthalpies:

$$
r=\frac{E_{b}^{\prime}-E_{6}}{E_{i}-E_{e}}=\frac{5.2-1.8}{7.8-1.8}=\frac{3.4}{6.0}=60 \%
$$

But this enthalpic efficiency is of no interest to us since the latent heat cannot be utilized (to do so condensation would have to be accepted in the dwelling). We shall therefore discuss only efficiency in temperatures. 
We should like to add that, by definition, in the case of equal flow rates, efficiency in enthalpies is limited in each case to a number below 1 since there is no way of directly restoring water vapor from one medium to the other and that the temperature of the forced-air intake after it has passed through the exchanger cannot evidently be greater than the temperature of the exhausted air. This statement does not apply in the case of unequal flow rates. As an example, when the flow rate of the forced-air intake is much higher than the flow rate of the exhausted air, and if the relative humidity of the outside air is 100 per cent, it is not theoretically impossible to reach an efficiency of 1 in "enthalpy" recovery. But in practice is this a very interesting case?

4.34 Supplementary Tests with Partial Obturation of the Exchanger Air Inlets and Outlets

As we have shown in Figure 17, exchanger outlets and inlets can be arranged to lengthen the average distance traveled by a fluid particle. Furthermore, this arrangement can be such that the circulation of the two streams is no longer purely a crossflow, but can at certain points be assimilated to a counterflow circulation.

The value of the additional pressure losses resulting from this arrangement were given in paragraph 4.31. The observed gain in efficiency is some three to five per cent, depending on the flow rates used.

The economic advantage of such an arrangement can be made evident only by an "optimization" calculation.

4.4 Study of Frost Formation

Appearance and Expansion of Frost 
When the outside temperature is very low, an area appears in the exchanger where the temperature of the plate surfaces on the extraction side is much lower than $0^{\circ} \mathrm{C}$. In these circumstances, and despite the highly turbulent character of the flow, water vapor in the exhausted air and condensed in suspension may deposit on the surface in the form of frost. If no change is made in the equipment's operation, a block of frost starts forming at the coldest point and then spreads out until the exchanger becomes clogged (see Figure 20). It is obvious that the risk involved in this instance is such that the colder the climatic region of the exchanger location, the greater the necessity to take preventive measures.

\section{Factors Having an Effect on the Occurrence of Frost and Its Rapid}

\section{Expansion}

A priorithese factors are:

--temperature of the forced (blown)-air intake (outside temperature),

--temperature of the exhausted air,

--humidity of the exhausted air,

--flow rates.

We shall indicate the qualitative effect of each one of these factors, as observed in the course of our tests.

--Outside temperature: occurrence of the frost-formation process is linked to this temperature. Theoretically, there is danger of frost forming whenever the temperature dips below $0^{\circ} \mathrm{C}$. In actuality the observed threshold is rather of the order of $-3^{\circ} \mathrm{C}$. It should be noted that in a real case this limit must be lowered even more because of the existence of various impurities in the exhausted air. 
The speed with which the process spreads is then an increasing function of the deviation between $0^{\circ} \mathrm{C}$ and the outside temperature.

-- Temperature of the exhausted air: its effect is counter to the preceeding effect. If the temperature of the exhausted air is $24^{\circ} \mathrm{C}$ instead of $20^{\circ} \mathrm{C}$, frost begins forming only at an outside temperature of $-5^{\circ} \mathrm{C}$ instead of $-3^{\circ} \mathrm{C}$.

..-- Humidity of exhausted air: the higher the humidity, the greater the risk of frost. In humidity conditions like those normally encountered in winter inside dwellings ( 30 to 60 per cent), this factor does, however, seem less important than the others.

-- Flow Rates (the situation considered is one in which exhaust and intake flow rates are close): the exhausted-air flow rate has no perceptible effect on the appearance of frost. On the other hand, the spread or expansion of the process is directly proportional to that flow rate.

\section{Effects of Frost}

The formation of frost has a highly unfavorable effect on the functioning of the exchanger and the ventilation system in general. It manifests itself in:

--a drop in exchanger effectiveness,

--an increase in pressure loss throughout the exchanger. This loss may be very substantial and completely alter the operation of the ventilation system. Furthermore, we note that the loss may occur during an off-period in the expansion of the frost mass because during that off-period the "density of the frost" remains "free" and becomes too great to allow 
sufficient cooling of the exhausted-air stream. This situation arises when in order to counter major pressure losses other than those of the exchanger, the ventilators (fans) in a ventilation system have a pressure (lo\&d) several times greater than the exchanger pressure loss. But this obviously does not constitute a feasibile "self-regulating" procedure.

Figure 21 shows that evolution of the pressure loss through the exchanger for different flow rates.

\section{Procedures Designed to Avoid Formation of Frost}

The patent statement which follows this report enumerates several solutions. At this point we shall mention only three of them:

The first solution considered was to equip the exchanger with a sliding panel or shutter that would deflect the exhausted-air flow away from the exchanger's coldest point (see Figure 22). Tests show that this solution was not entirely satisfactory. It was therefore rejected.

A second solution involved preheating the forced-air intake before it passed into the exchanger. In this way the temperature of that air would be raised above the threshold of initial frost formation. The economic aspects of such a method will be examined later in this report. Notice that this procedure does have the advantage of not creating any discontinuity in forced-air intake temperatures during the winter, as the third solution described below does.

The annual fuel consumption required for this preheating is very low. In the Paris area, during an average winter and with the preheating raising the air temperature to $0^{\circ} \mathrm{C}$, this consumption represents only one per cent of the total heating requirement. 
A third solution consists in providing an exchanger by-pass so that the cold forced-air intake does not flow through the exchanger when frost is being formed. This device can be controlled by:

--either a differential pressure controller ("pressostat") that detects any abnormal rise in pressure loss throughout the exchanger (see Figure 23),

--or, in an open aperture, by a regulator "slaved" to the outside temperature (a "pressotat" may be installed for additional security).

This method has the disadvantage of introducing temperature fluctuations in the forced-air intake which can cause condensation, periodic expansions, etc. . . It may be noted that in a large-size system there is still the possibility of introducing limited heating into the by-pass. In this event, however, the advantage over the preceding method is no longer evident.

\subsection{Conclusion}

The tests conducted on the prototype exchanger built at the CSTB permitted us to draw certain conclusions or rules on the behavior of a cross-flow exchanger of this type:

--Its efficiency can be advantageous--of the order of 70 per cent--for pressure losses that are not excessive.

--Disadvantages stemming from frost formation can be eliminated by use of a suitable device.

Since the dimensions of the prototype exchanger were arbitrarily chosen, we shall endeavor to determine those dimensions and flow rates conducive to optimum exchanger utilization, by calculations based on the 
data and results obtained experimentally.

5. EXTENSION OF EXPERIMENTAL RESULTS BY COMPUTER CALCULATION.

\subsection{Calculation of Exchanger Efficiency}

Let us take a crossflow exchanger and assign subscript $i$ to the exhausted air and subscript 2 to the forced-air intake. Temperatures $t_{i}$ and $t_{2}$ at a point in the exchanger are a function of the $x_{1}$ and $x_{2}$ coordinates of that point, as defined in Figure 24. When the flows are laminar variations $t_{1}$ and $t_{2}$ in space may be expressed by the differential equations:

$$
\left\{\begin{array}{l}
\frac{\partial t_{1}}{\partial x_{1}}=k_{1}\left(t_{2}-t_{1}\right) . \\
\frac{\partial t_{2}}{\partial x_{2}}=k_{2}\left(t_{1}-t_{2}\right) .
\end{array}\right.
$$

where coefficients $k_{1}$ and $k_{2}$ are function:

--of the exchanger characteristics: nature and shape of plates, distance between them,

--of the "flow-rate density" of the air stream being considered, that is to say of the flow rate divided by the width of the exchanger and the number of plates.

--of the temperature of the air current.

Knowing functions $k_{1}$ and $k_{2}$ and the temperatures at the inlet to the exchanger, $t_{i}$ and $t_{e}$, we can gradually calculate the temperature field in each flow, and therefore temperatures at the exchanger outlet, and therefore the efficiency. This calculation can be done quite easily with a computer. A program has been written for this purpose at the CSTB. 
In the practical example we have under study flows are not laminar. But nevertheless, the above theoretical representation can be used with sufficient approximation. Moreover, as temperatures remain within a relatively limited interval, it may be assumed that $k_{1}$ and $k_{2}$ are constant in space. And lastly, if the flow rates of both fluids are equal, and if the exchanger is square, by symmetry we have equality between $\mathrm{k}_{1}$ and $\mathrm{k}_{2}$. We shall assume that situation for this computation.

Efficiency is expressed:

$$
r=\frac{\frac{1}{L} \int_{0}^{L} t_{2}\left(x_{1}, L\right) d x_{1}-\frac{1}{L} \int_{0}^{L} t_{2}\left(x_{1}, 0\right) d x_{1}}{\frac{1}{L} \int_{0}^{L} t_{1}\left(0, x_{1}\right) d x_{2}-\frac{1}{L} \int_{0}^{L} t_{2}\left(x_{1}, 0\right) d x_{1}}
$$

where $\mathrm{L}=$ width of the exchanger.

$$
t_{1}\left(0, x_{1}\right) \text { and } t_{2}\left(x_{1}, 0\right) \text { are constants equal to } t_{1} \text { and } t_{2}
$$
respectively, so that the above expression may be written simply as:

$$
r=\frac{\frac{1}{L} \int_{0}^{\bar{L}} t_{2}\left(x_{1}, \mathrm{~L}\right) d x_{1}-t_{e}}{t_{i}-t_{e}}
$$

For a given value of $k, r$ depends only on $\mathrm{L}$. Figure 25 shows the variation of $r$ as a function of $L$ for $k=8 \mathrm{~m}^{-1}$. This variation was determined by computer calculation with the program mentioned above.

It follows from the form of the differential equations (1) that if we know an $r_{0}$ function $\left(L, k_{0}\right.$ ) of $r$ as a function of $L$, we know every $r$ function ( $I, k$ ) by the transformation:

$$
r(\mathrm{~L}, k)=r_{0}\left(\mathrm{~L} \frac{k}{k_{0}}, k_{0}\right)
$$

By applying the method of computation just outlined, it is possible to determine the efficiency of an exchanger of any dimensions, when knowing the efficiency, determined experimentally, of an exchanger fabricated with 
the same plates. We made this determination for our type of exchanger. The result presented in Figure 28, is depicted by two curves. The first gives the variation of efficiency $r$ as a function of the product $\lambda \mathrm{X} \mathrm{L} / \mathrm{L}_{0}$, with $L_{o}$ being the length of the prototype, $L$ the length of the exchanger being considered, and $\lambda$ the coefficient function of the ratio of the "flow-rate densities," $d / d_{0}$, of the two exchangers (let us recall that the density of the flow rate is equal to the total flow rate $D$ divided by the width $\mathrm{L}$ of the exchanger and by the number $\mathrm{n}$ of its plates). The second curve gives the variation of $\lambda$ with $d / d_{0}$.

\subsection{Calculation of Pressure Loss}

Pressure losses at the inlet and outlet of the exchanger are negligible when viewed against the losses that occur along the distance covered between the plates. Pressure loss through the exchanger is consequently:

--proportional to the width $L$ of the plates;

--function of the flow-rate density d;

--measurements showed that this function is essentially of form $d^{2}$.

Therefore, between pressure losses $h_{0}$ and $h$ of two exchangers of $L_{0}$ and $L$ sizes and flow-rate densities $d_{0}$ and $d$, there is the relation:

$$
h=h_{0} \frac{\mathrm{L}}{\mathrm{L}_{0}}\left(\frac{d}{d_{0}}\right)^{2}
$$

This provides a means of calculating the pressure loss through an exchanger of the same nature as the prototype exchanger, but of different size and flow-rate density.

In the next chapter we shall show how the equations just established for efficiency and pressure loss will enable us to calculate the optimum 
dimensions of the exchanger under given conditions.

\section{ECONOMIC AND INDUSTRIAL ASPECTS}

We shall first compute the savings in heating achieved by use of an exchanger, and also calculate that exchanger cost which must not be exceeded if it is to be a cost-effective proposition.

We shall then show how to determine, for given conditions, the optimum dimensions of an exchanger whose prototype has previously been laboratory tested.

6.1 Computation of Savings in Heating Obtained with an Exchanger, and the Latter's Cost-Effectiveness Threshold.

Although the presence of an exchanger does reduce heating costs, it does, on the other hand, entail an increased pressure loss which in turn increases ventilation costs. The reduction in heating costs and the increase in ventilation costs must be computed for both initial investment costs and operating costs.

\subsection{Savings in Heating}

We shall compute the savings for one cubic meter per hour of incoming air passing through the exchanger.

The investment savings is equal to $c\left(t_{i}-t_{e}\right) i$, where $c=$ specific heat of the air, or $0.3 \mathrm{kcal} /{ }^{\circ} \mathrm{C} ; t_{i}=$ basic inside temperature, in dwellings generally taken as equal to $20^{\circ} \mathrm{C} ; t_{e}=$ basic outside temperature whole value depends on the building site and location; $i$ = marginal price of the installed $\mathrm{kcal} / \mathrm{h}$.

Operating savings are equal to $c 24 \mathrm{D}_{j} f$ where $c=$ specific heat of 
the air, already mentioned above; $D_{j}=$ value of the degree-days of heating at the building location; $f=$ maximum price of the consumed or expended kcal.

Values of $i$ and $f$ are function of numerous factors: type of heating (individual, collective for a multi-story (apartment) building, collective for a group or block of houses and/or buildings), fuel, boiler-room or furnace-room facilities, flexibility and regulation. . . Our computations will be for average values which we will take as equal to:

--0.4 francs per installed $\mathrm{kcal} / \mathrm{h}$ (i)

-0.00003 francs per consumed kcal (f)

And lastly, we shall compute for three pairs of values of $t_{e}$ and $D_{j}$ corresponding to about the average of these values for each of the climatic zones, A, B, C, defined in the CSTB Technical Report:
Zone $\mathrm{A}: \mathrm{t}_{\mathrm{e}}=-15^{\circ}$
$D_{j}=2800$
Zone $\mathrm{B}: \mathrm{t}_{\mathrm{e}}=-10^{\circ}$
$D_{j}=2300$
Zone $\mathrm{C}: \mathrm{t}_{\mathrm{e}}=-5^{\circ}$
$D_{j}=1800$

The savings obtained under these conditions are as follows:

\section{Investment Savings}

Zone A

4.20 francs

Zone B

3.60 francs

3.00 francs

Zone C

\section{Operating Savings}

0.60 francs per year

0.50 francs per year

0.40 francs per year

6.12 Cost of Increased Ventilator (fan) Capacity

The investment and operating expenditures entailed in augmenting the capacity of the ventilator fans depends, as in the case of heating savings, on various factors, and first and foremost on the exchanger 
pressure loss (the expenditures may be estimated as almost directly proportional to the loss). But fortunately these expenditures remain relatively low when compared to the savings in heating. Therefore, in the computations made in this paragraph we shall take only one value, namely the one for a pressure loss of the order of 200 Pascal. This is the loss that exchangers designed after our prototype should have. The figures retained are as follows $\left(\right.$ per $\left.\mathrm{m}^{3} / \mathrm{h}\right)$ :

--in investment expenditures: 0.25 francs

--in operating expenditures: 0.10 francs per year

\subsection{Summary Analysis}

Table 1 is a compilation of:

--the values given above, i.e., for savings in heating and for expenses incurred in augmenting ventilator-fan capacities, per $\mathrm{m}^{3} / \mathrm{h}$;

--the difference between these savings and expenditures, still per $\mathrm{m}^{3} / \mathrm{h}$;

--operating savings expressed as investment savings for an interest rate and amortization period of 10 years: Doing this involved multiplying by the factor:

$$
\frac{1}{(1+0.1)}+\frac{1}{(1+0.1)^{2}}+\ldots . .+\frac{1}{(1+01)^{10}}=6.15
$$

-- overall savings expressed as investment savings, still per $\mathrm{m}^{3} / \mathrm{h}$;

--values obtained when the preceding figure is multiplied either by 180 or 3600 (the former gives the approximate savings per dwelling, the latter per 20 dwellings/apartment). 
To be sure these are approximate figures, but, nevertheless, they do fix the order of magnitude of that exchanger cost ceiling which must not be exceeded if use of the exchanger is to be profitable. The following expenses must be included in that exchanger cost: initial investment, maintenance and service, replacement of plates if the "expendable"-plate solution is selected.

Our estimates seem to show that there should be no difficulty in staying below the cost-effectiveness or profitability threshold we have just computed.

Table I

Zone A

Zone B

Zone $\mathrm{C}$

Savings in heating per $\mathrm{M}^{3} / \mathrm{h}$

in investment costs

4.20 francs

0.60 francs

3.60

0.50

3.00

in operatings costs

per year

Expenses due to increased capacity

of ventilator fans per $\mathrm{m}^{3} / \mathrm{h}$

In investment costs

0.25 francs

0.25

0.10 francs

0.10

0.25

in operating costs

per year

Differences between savings

and expenditures per $\mathrm{M} / \mathrm{h}$

in investments
in operations
3.95 francs

0.50 francs

per year
3.35

0.40

2.75

0.30

\section{Operating savings expressed}

as investment savings

3.05 francs

2.45

1.85

Overall savings expressed

as investment savings

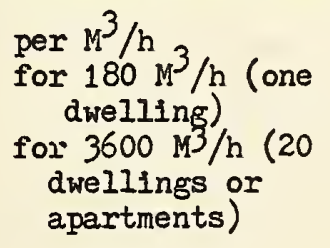

$\begin{array}{ccc}7.00 \text { francs } & 5.80 & 4.60 \\ 1260 \text { francs } & 1045 & 830 \\ 25,200 \text { francs } & 20,900 & 16,600\end{array}$


Our computation did not take the forced-air intake duct into account. We assume that such a system is required for example, because the dwelling in question is in a noisy area (windows cannot be opened). However, if this duct cost is taken into account, then we find that it is difficult if not impossible to make the exchanger a profitable proposition. Use of the exchanger therefore implies that a mechanical forced-air intake is warranted for some other reasons, at least in part. In such a situation the employment of the exchanger may be theladitional determining factor.

\subsection{Method of Computing Optimum Exchanger Dimensions}

In general, there are two types of exchangers worthy of consideration:

1. Exchangers designed to handle high flow rates (multipleoccupancy buildings). In this case, the pile of plates may consist of an assembly of a certain number of standardized basic modules.

2. Exchangers designed for an individual dwelling. In this case the most attractive choice appears to be a single compact unit containing the ventilation fans, the exchanger with its anti-frost system, and the filters if these are provided.

For both types, the manufacturer would find it advantageous--if only to facilitate the replacement of plates--to offer a very limited line of units or modules. Thus the manufacturer should determine the optimum dimensions of these units or modules. Then the user will select the optimum unit or the optimum number of modules to fit his particular situation. We shall show how such optimization computation may be made.

We shall consider the problem in its general aspects. 
Given: flow rate $D$ to be handled, and interest rate $\tau$ and an amortization period of $\mathrm{N}$ years. It is assumed that the exchanger selected has square plates and a geometry identical to that of a prototype whose performance characteristics have been determined by laboratory tests. The problem is to determine the length $L$ of the exchanger and number $n$ of plates conducive to the least overall cost (investment expense and operating expense).

We propose to examine successively each of the elements entering into these expenses so as to see which of them are affected by $L$ and $n$ and, if so, how these characteristics do affect them. 6.21 Savings in Heating

Savings in heating, with respect to both investment and operating costs, is proportional to the efficiency of the exchanger. As we saw in paragraph 5.1 that efficiency depends upon length $L$ and flow-density d. Since for a given flow rate $d$ is inversely proportional to $L$ and $n$, in the final analysis efficiency depends only on $\mathrm{L}$ and $\mathrm{n}$. In paragraph 5.1 we described how it was possible to calculate $r$ as a function of $L$ and $d$, thus of $\tau$ and $n$.

And in paragraph 6.11 we showed how, knowing the efficiency of the exchanger, the savings in heating costs could be computed. 6.22 Cost Due to Increased Ventilator-Fan Capacity.

We may assume, with sufficient approximation for this computation, that the cost--investment and operating--of the increased capacity of the ventilator fans is proportional to pressure loss.

In paragraph 5.2 we saw that this pressure loss is itself proportional to the length $L$ of the exchanger and to the square of density of flow $d$. 
As, for a given rate of flow, $d$ is inversely proportional to $\mathrm{n}$ and $\mathrm{L}$, pressure loss is finally inversely proportional to $\mathrm{Ln}^{2}$.

And in paragraph 6.12 we gave the order of magnitude of the investment and operating costs for an exchanger pressure loss of 200 Pascal.

\subsection{Exchanger Cost}

We may consider two parts in the exchanger:

1. The plates which in our preferred solution are to be replaced annually. Their cost should be counted as an operating cost. The cost of a plate is divided approximately into a fixed part and a part proportional to the square of the length $L$ of the exchanger. Therefore, for $n$ plates we have a cost equal to $n\left(a+b L^{2}\right)$, where $a$ and $b$ are constants.

2. The rest of the exchanger (case, defrosting system) and its connection to ventilation circuits. It may be assumed as a first approximation that this cost is independent of exchanger size (the cost approximately breaks down into a fixed part and a part proportional to flow rate).

A few operating costs should be added to the above (maintenance and service, operation of the defrosting equipment is so equipped). These costs are practically independent of the exchanger dimensional characteristics $L$ and $n$.

\subsection{Summary}

We have not, for the moment, worked with a manufacturer on this matter. We therefore do not have sufficiently precise data on the price of the exchanger or plates to be able to present an optimization computation. 
But the particular purpose of this paragraph was to show how such a computation can be done.

\section{CONCLUSION}

The solution studied at the CSTB for a system designed to recover heat from ventilating air, appears satisfactory from the sanitary and hygienic aspect and also from the viewpoint of economy and savings.

\section{APPENDIX}

\section{-- COMPUTATION RELEVANT TO HUMIDIFICATION OF THE AIR IN A DWELLING}

By following the psychrometric chart in Figure 19, we shall consider a day during which the weight of water vapor in the air is two grams per kilogram of air. Taken at $21^{\circ} \mathrm{C}$ this gives a relative humidity of 13 per cent. But inside a room there is a certain reduction of the water vapor which we may estimate to be approximately 30 grams per hour, providing the dwelling is properly ventilated. If the air change in this room is $30 \mathrm{~m}^{3} / \mathrm{h}$, this means that the air in that room contains per $\mathrm{m}^{3}$, i.e., as a first approximation per $\mathrm{kg}$, one gram more than the outside air. Therefore, there will be 3 grams per kilogram of air which corresponds to a relative humidity of 20 per cent.

To obtain 35 per cent, that is 5.3 grams per kilogram of air, requires the evaporation of 2.3 grams per $\mathrm{m}^{3}$ per hour, or approximately 1.7 liters for $30 \mathrm{~m}^{3}$ and 24 hours. 
The figures given in paragraph 2 of Chapter 1 (Introduction), result from computation and statistics compiled from meteorological data obtained at Paris-le-Bourget. The data show that on an average (average winter 1960 to 1964) there are:

--8 days during which the weight of the water vapor is between one and two grams,

--20 days when it is between two and three grams,

--37 days when it is between two and four grams,

--44 days when it is between four and five grams.

The relative humidity in the room under consideration is equal to 13 , $20,26,32$, and 39 per cent for respectively 1, 2, 3, 4, and 5 grams of water per kilogram of outside air. Extrapolation of these figures shows that the relative humidity in this room will be:

--below 20 per cent during 8 days,

--between 20 and 25 per cent during 16 days,

--between 25 and 30 per cent during 28 days,

--between 30 and 35 per cent during 30 days.

\section{Conversion pactors}

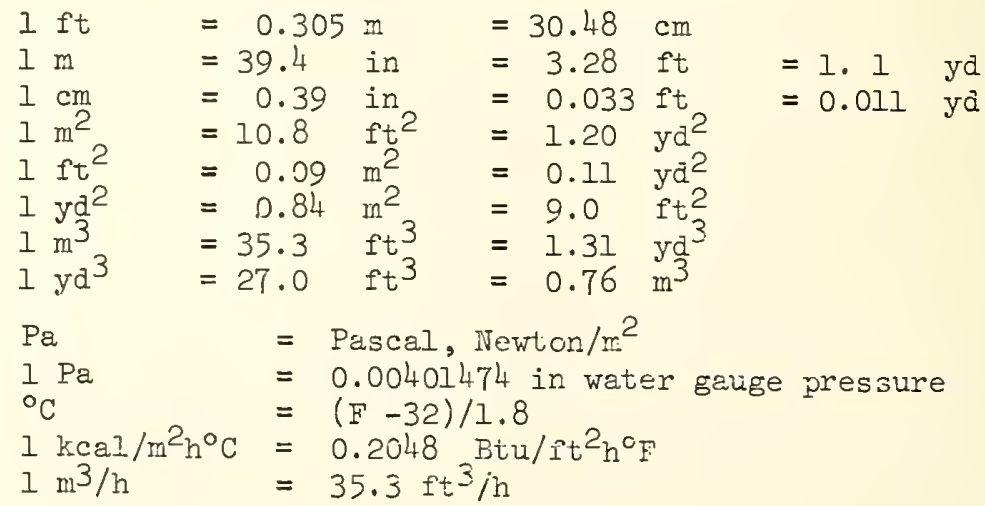




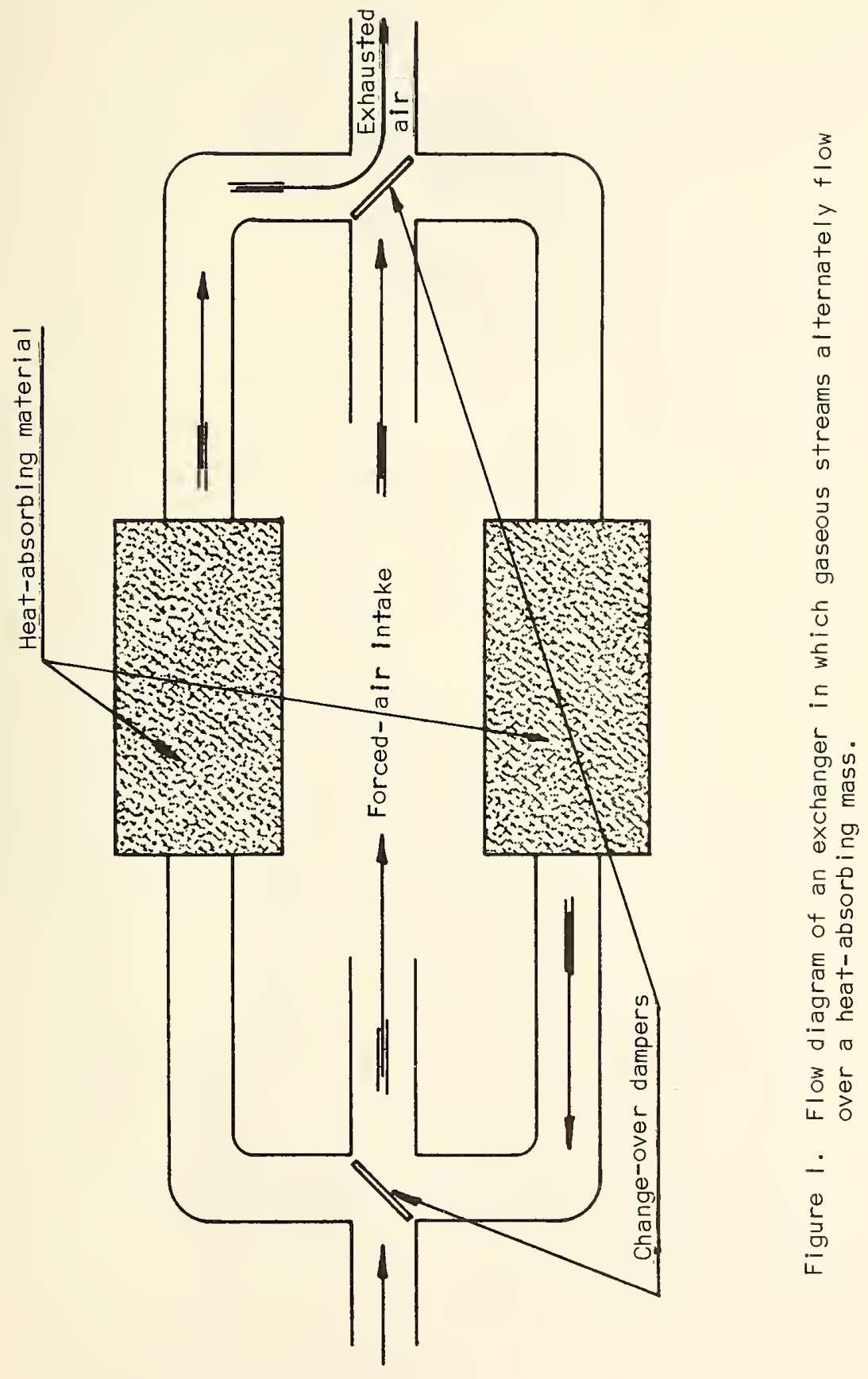




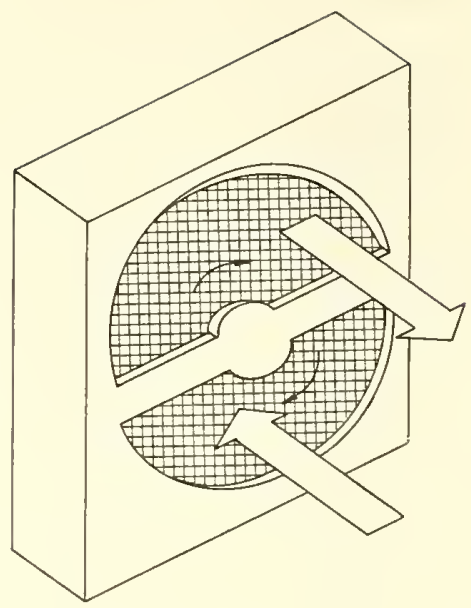

Figure 2. Sketch of exchanger with thermal wheel.

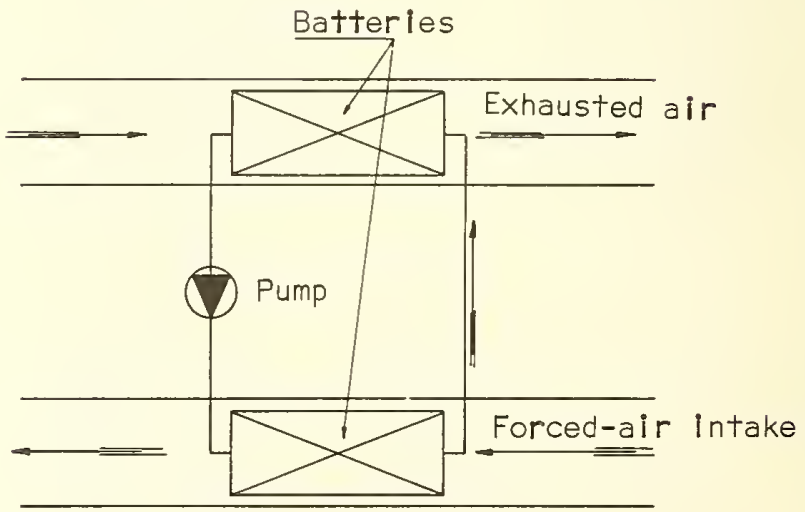

Figure 3. Exchanger using an intermediary heat-carrying fluid. 


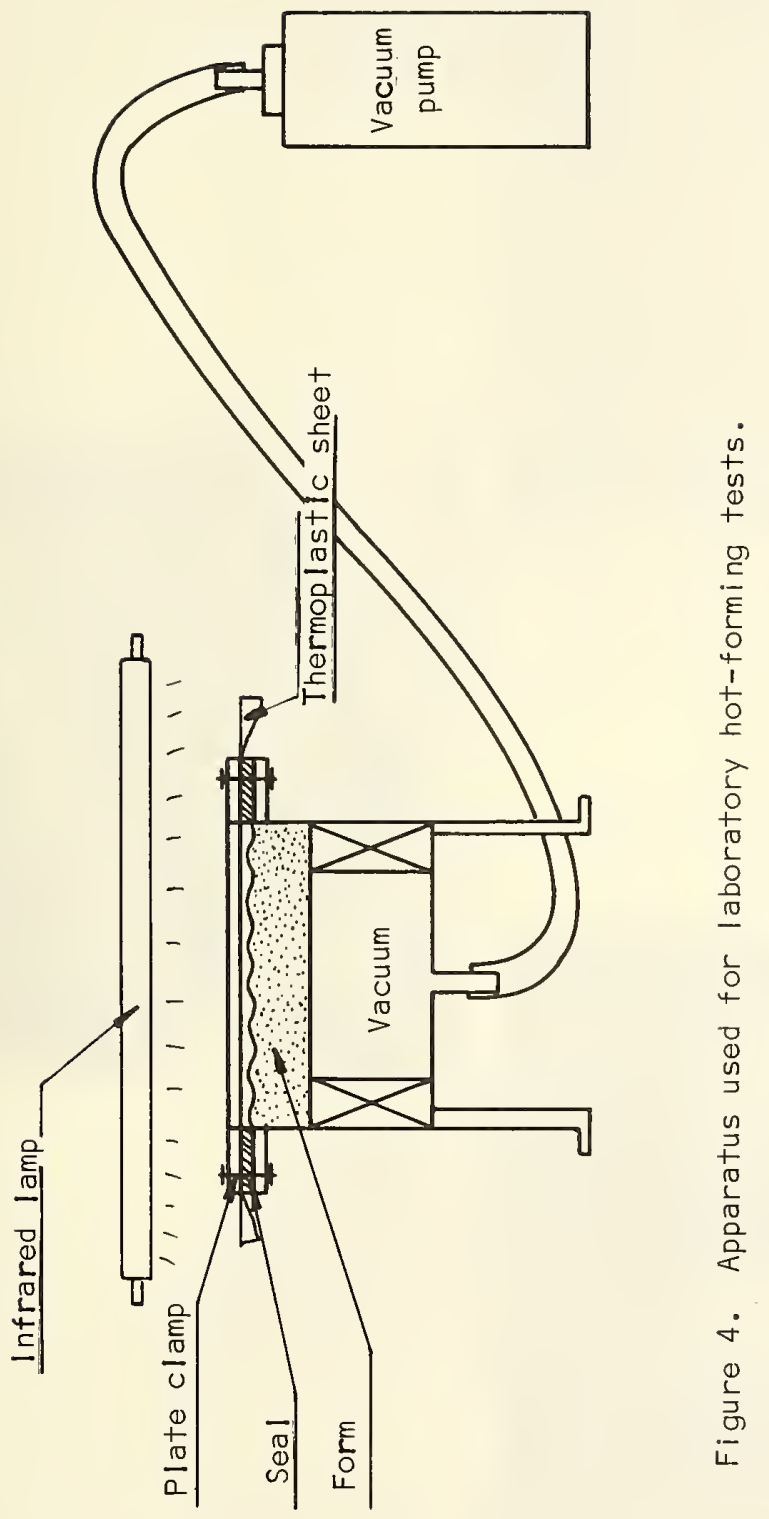




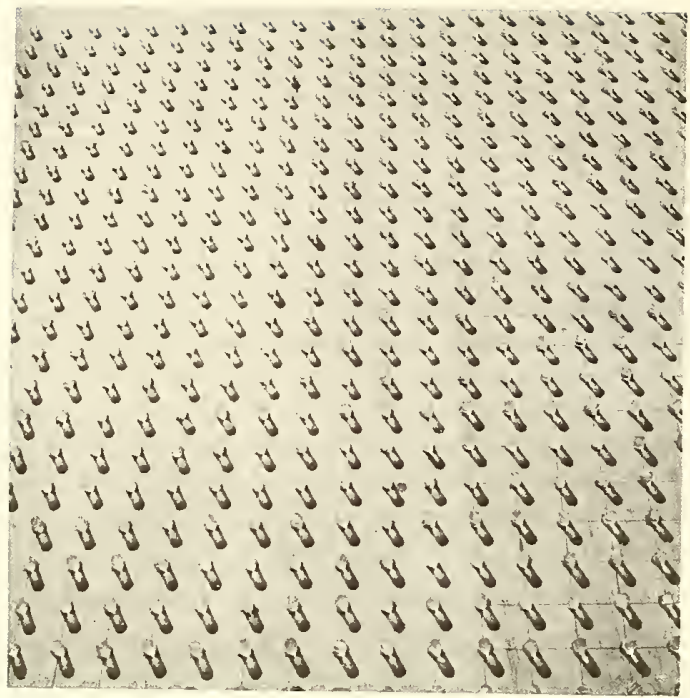

Figure 5

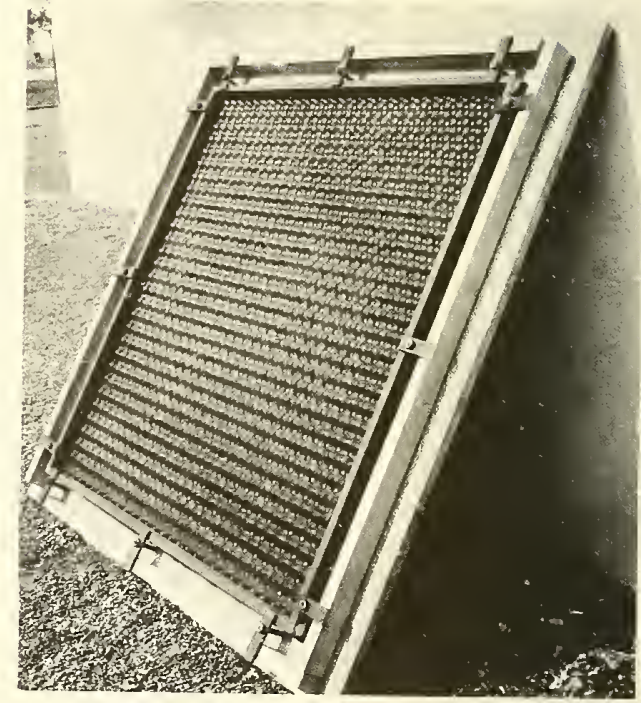

Figure 6

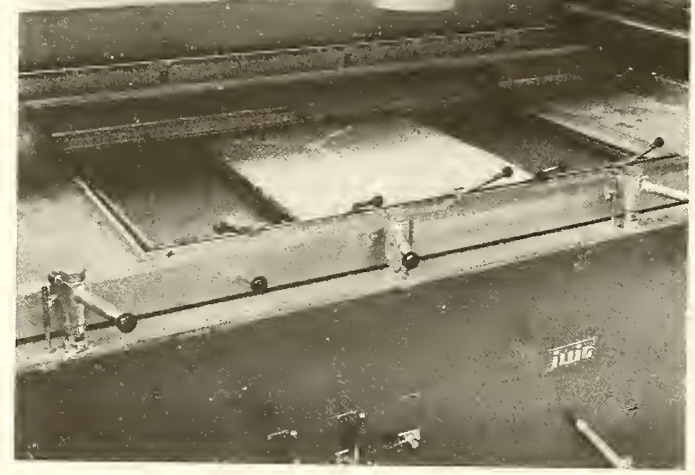

Figure 7 

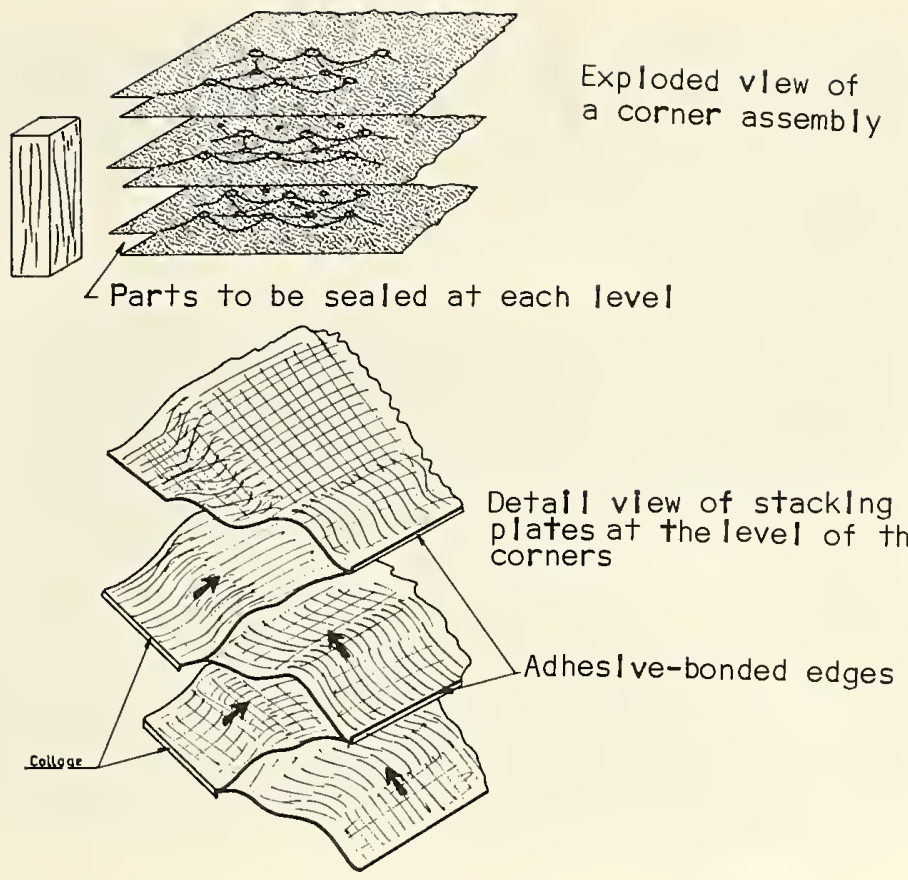

Figure 8. Assembling of plates

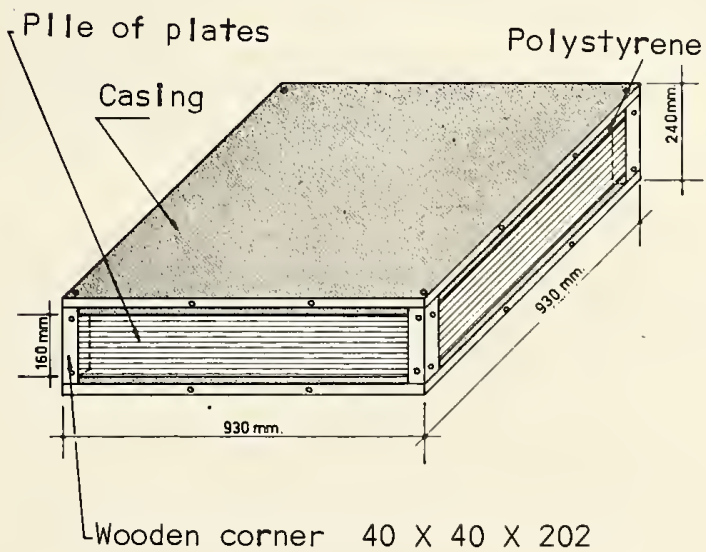

Figure 9. Exchanger unit 


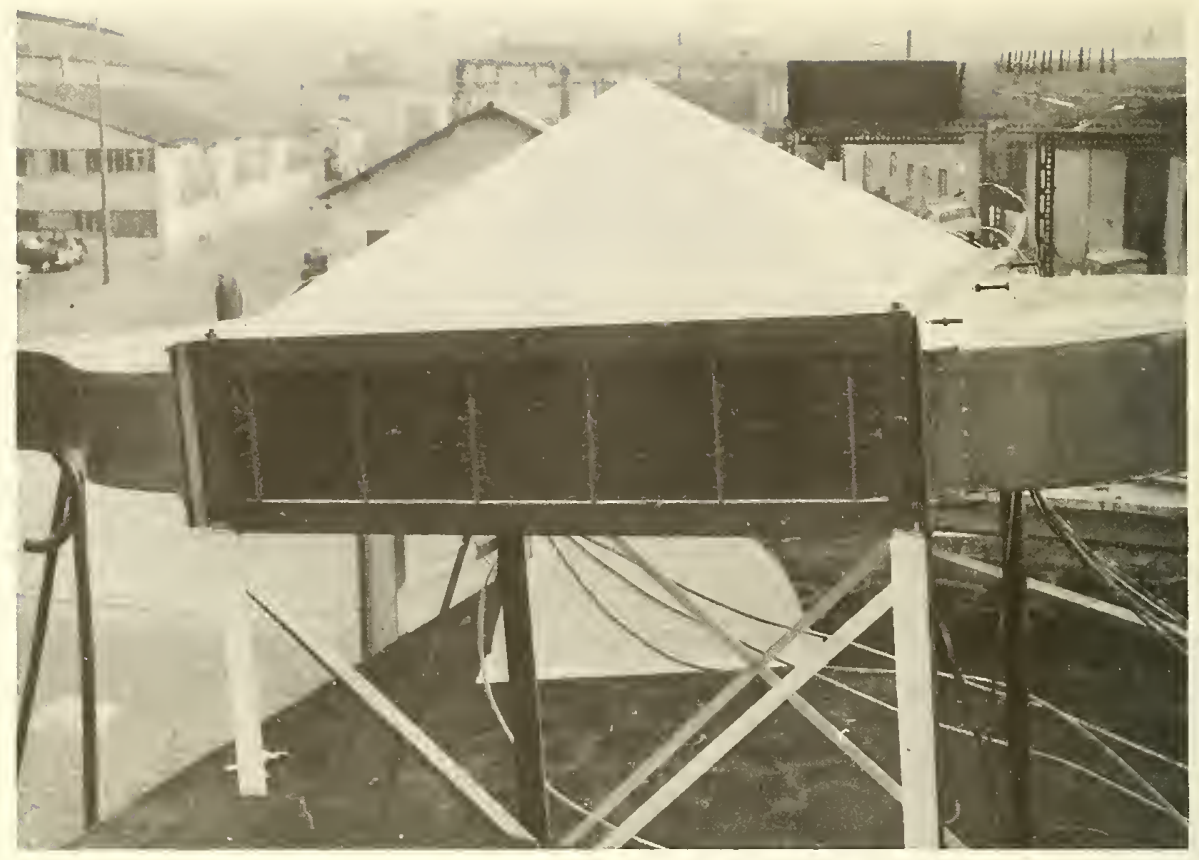

Figure 10

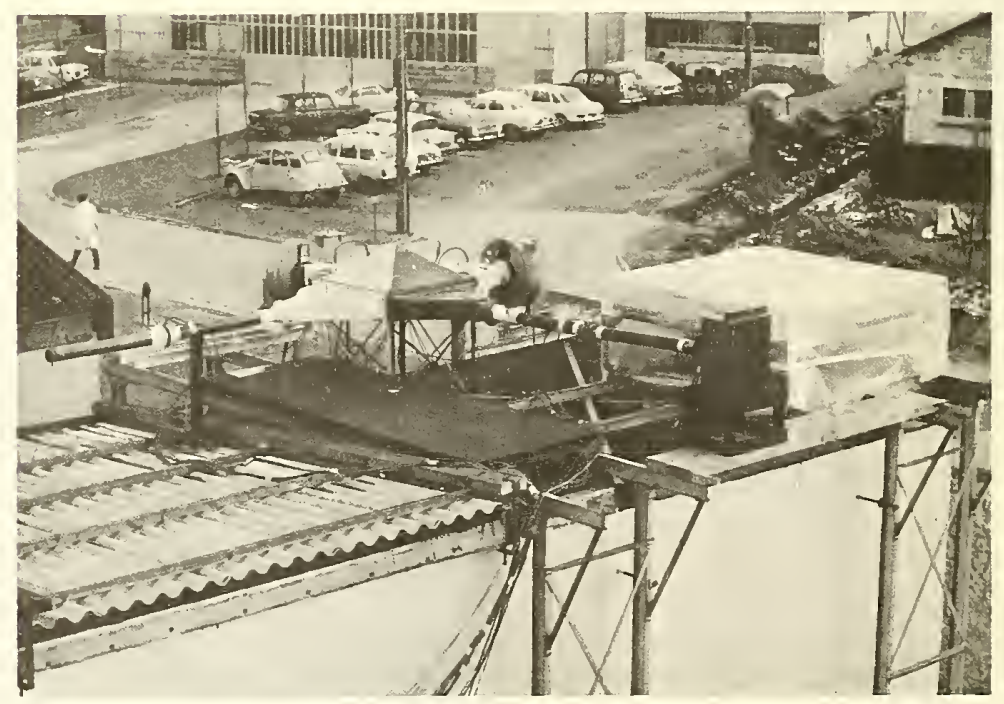

Figure II 


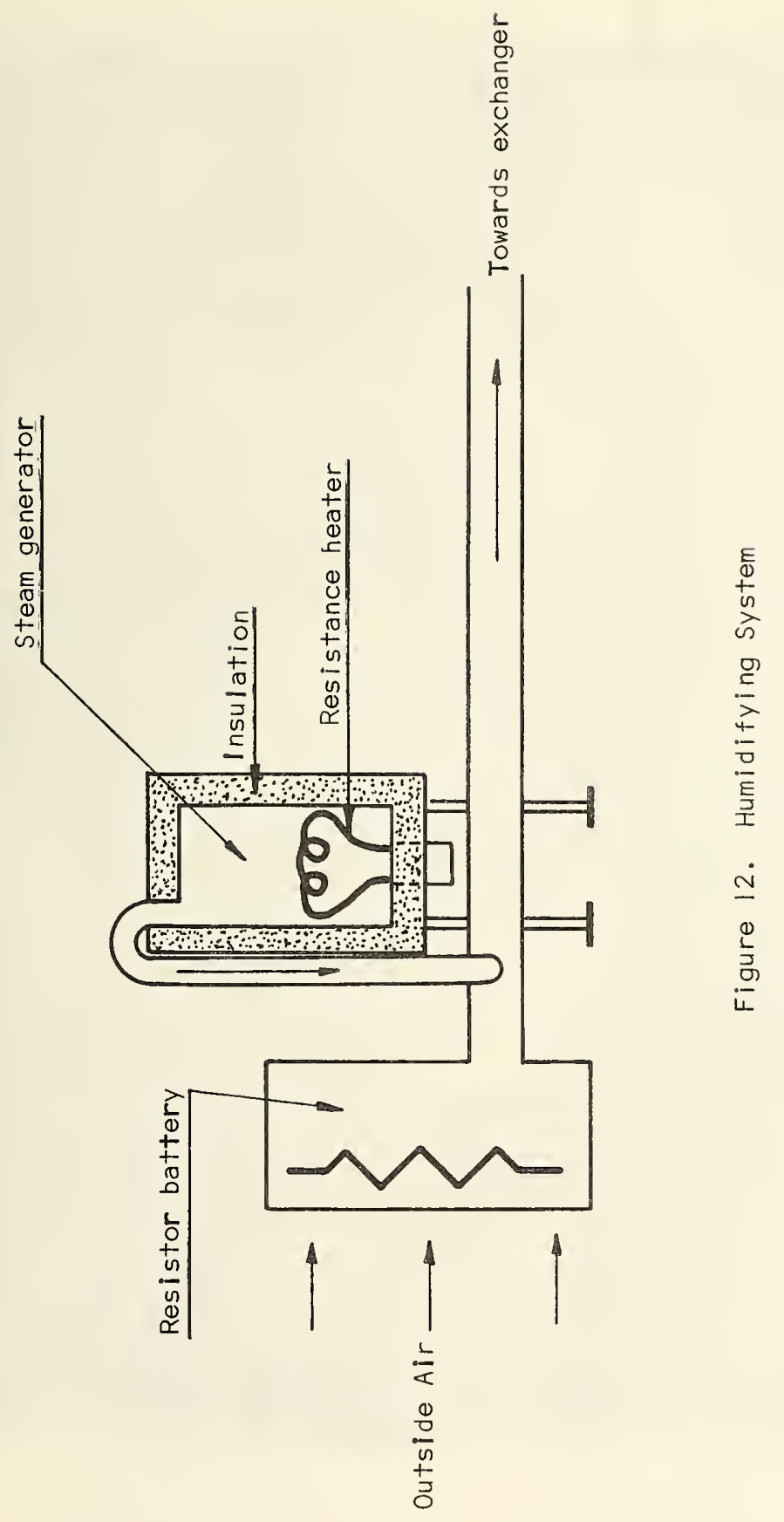




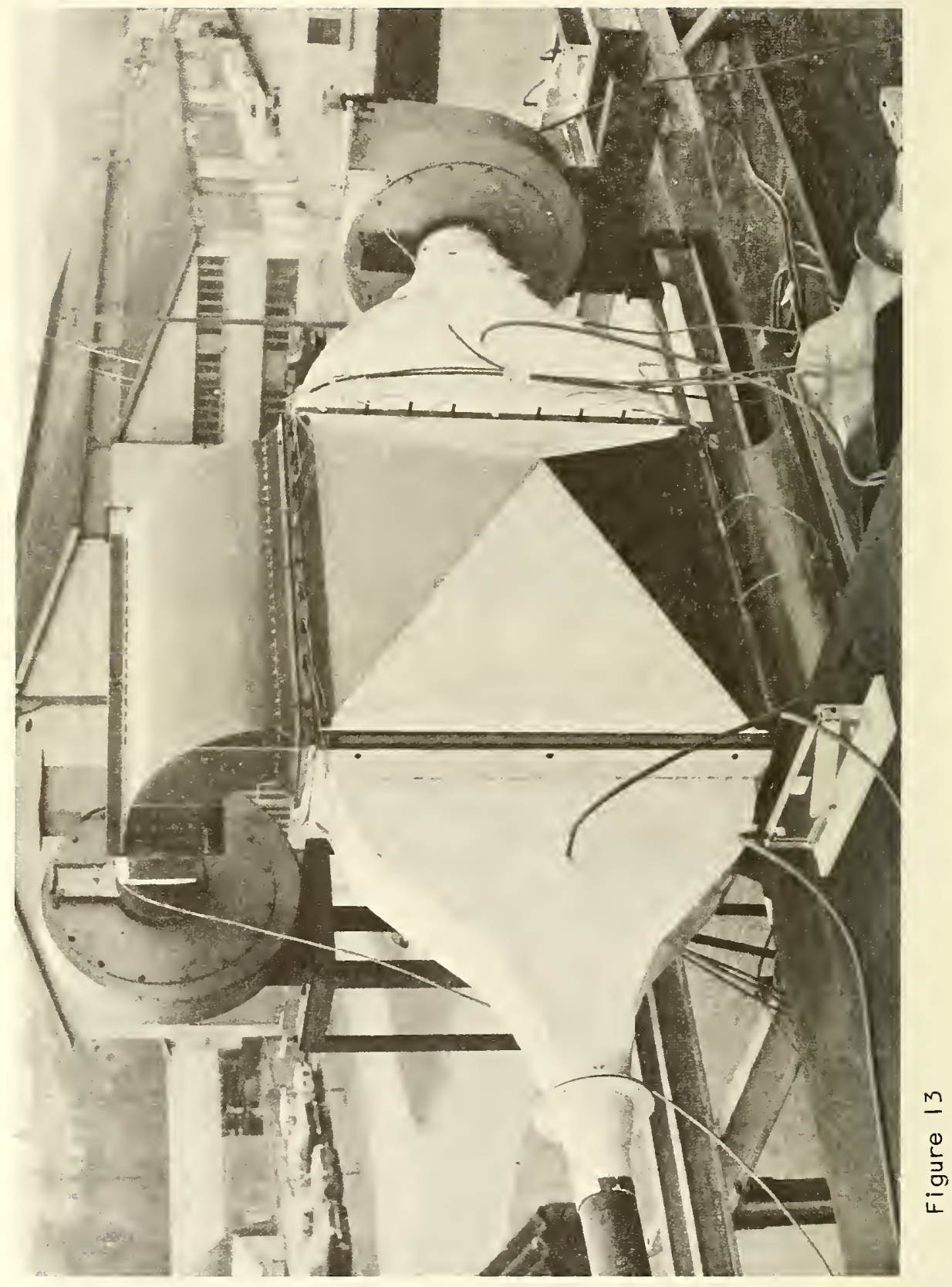




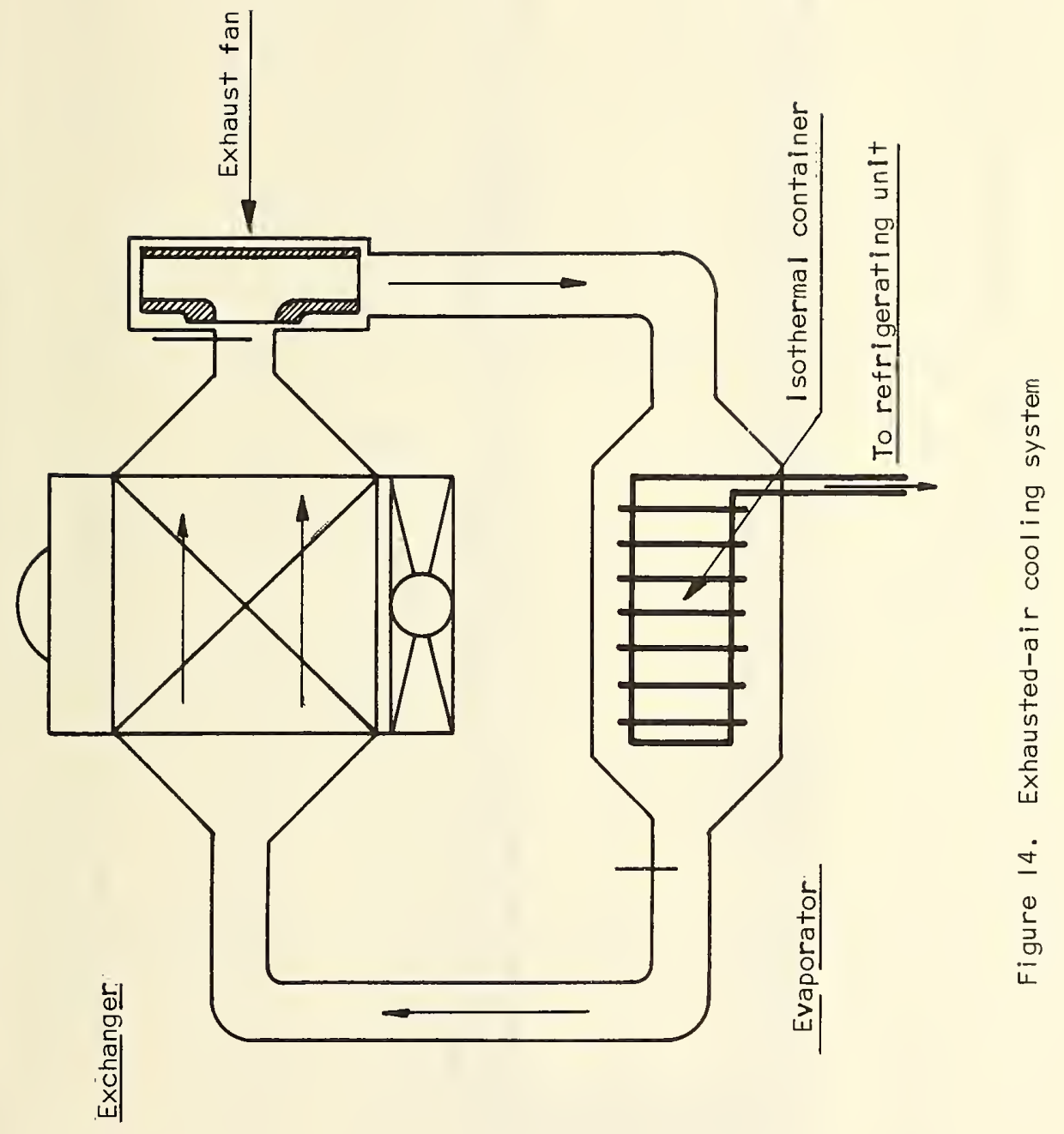




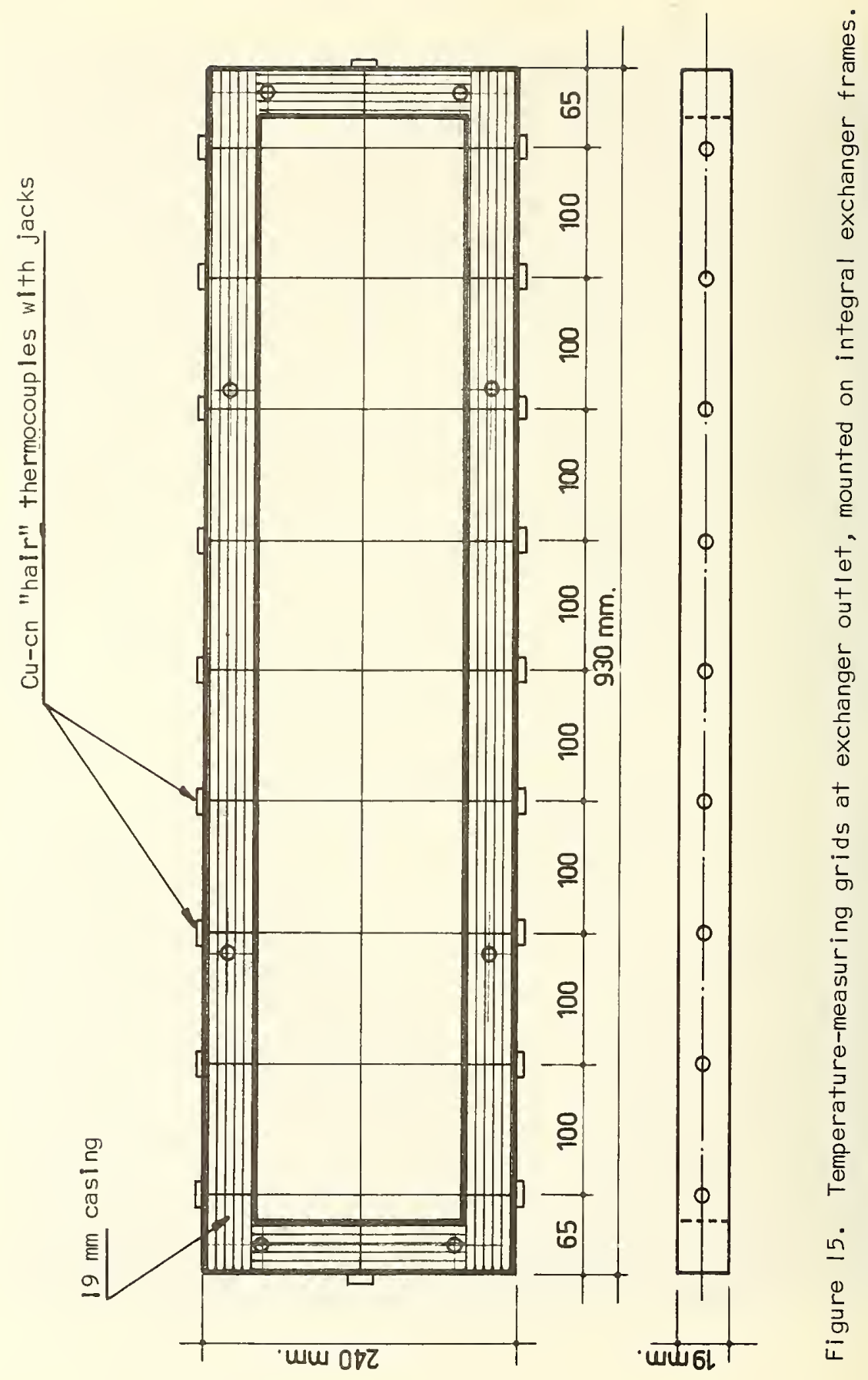




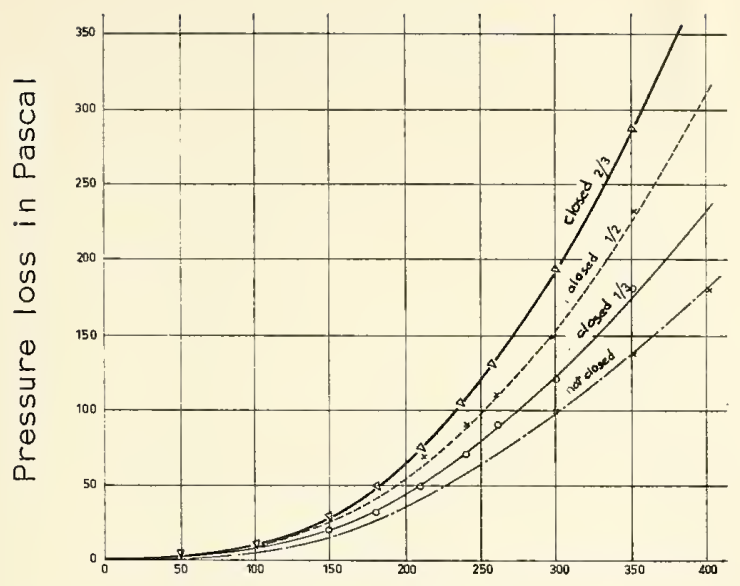

Flow rate in $\mathrm{m} 3 / \mathrm{h}$

Figure 16. Exchanger pressure loss as function of flow rate

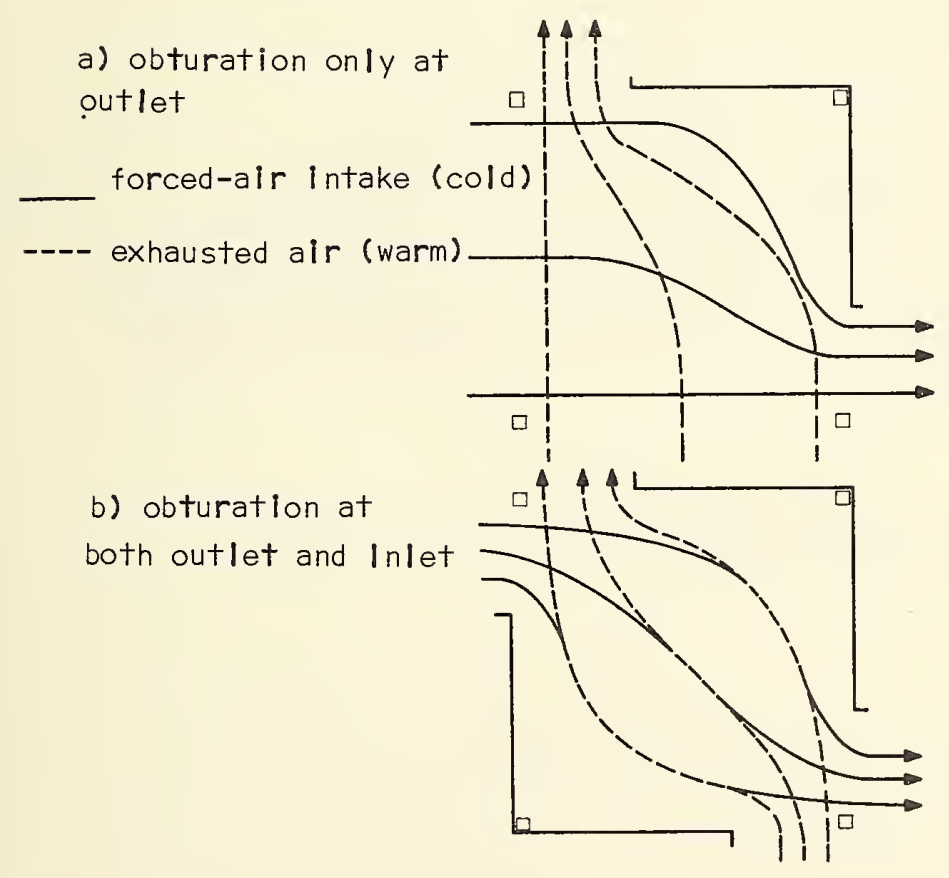

Figure 17. Diagram of partial obturation of exchanger 


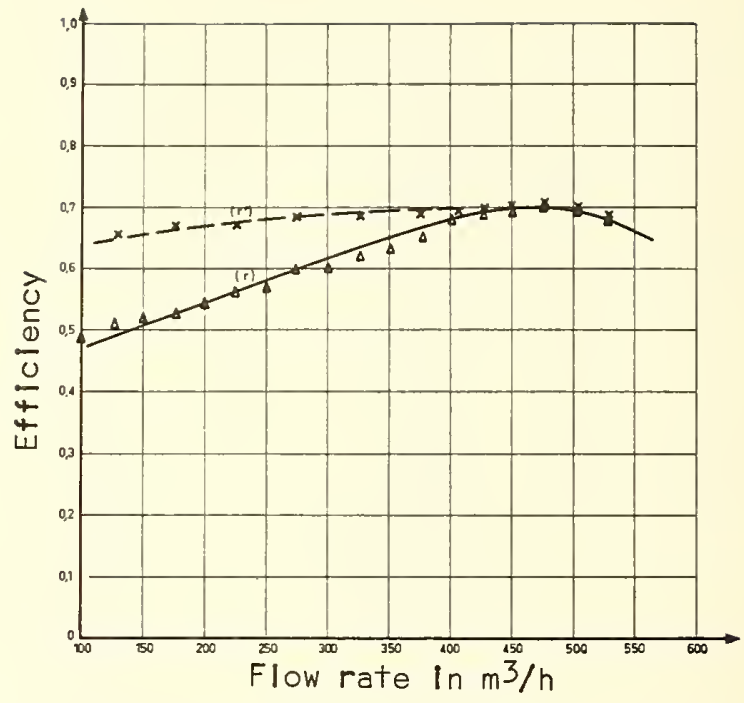

Figure 18. Variation of exchanger efficiency as function of flow rate, when exhaust flow rate and forced-air intake flow rate are equal. 


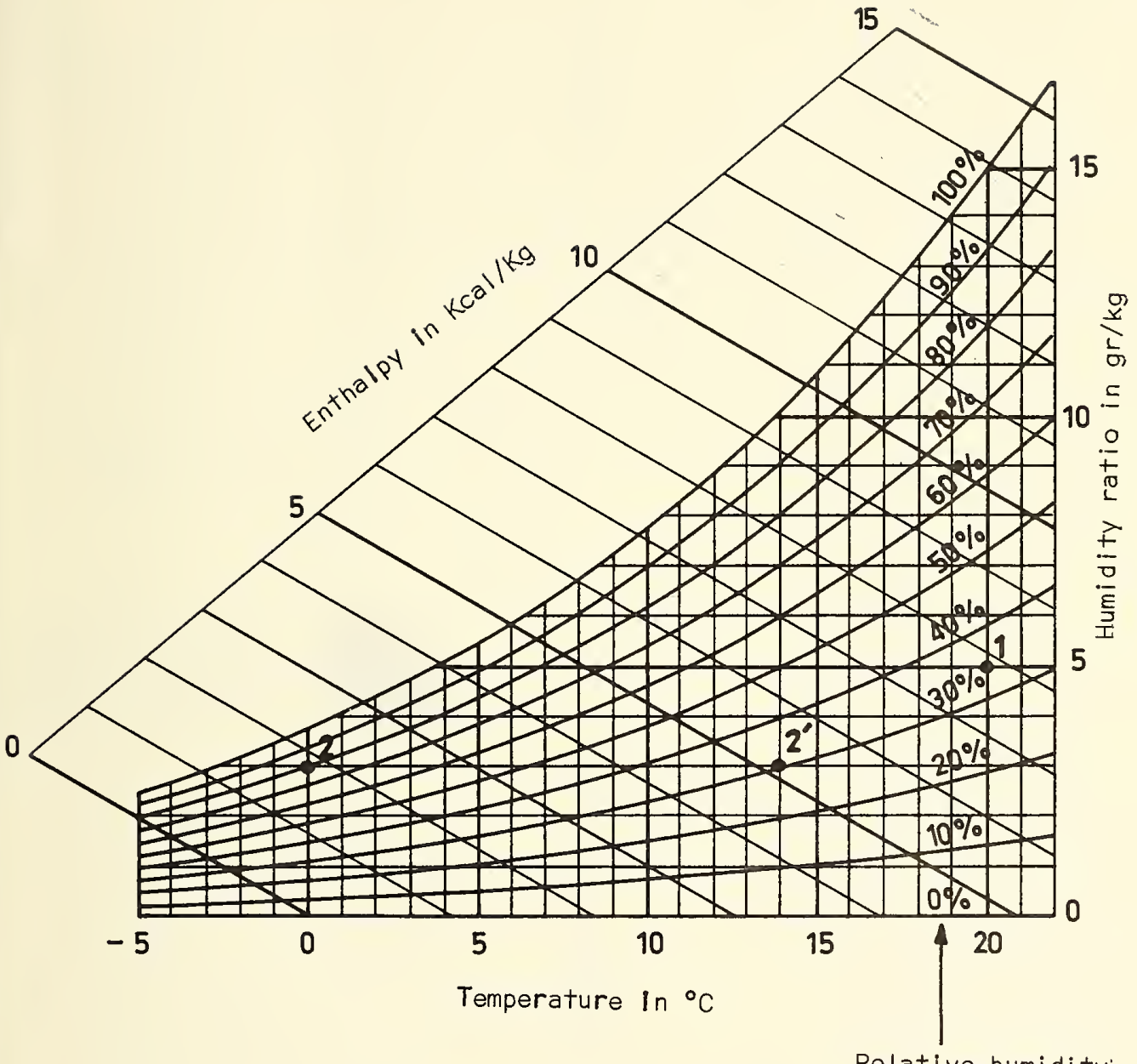

Relative humidity

Figure 19. 
Forced-air intake

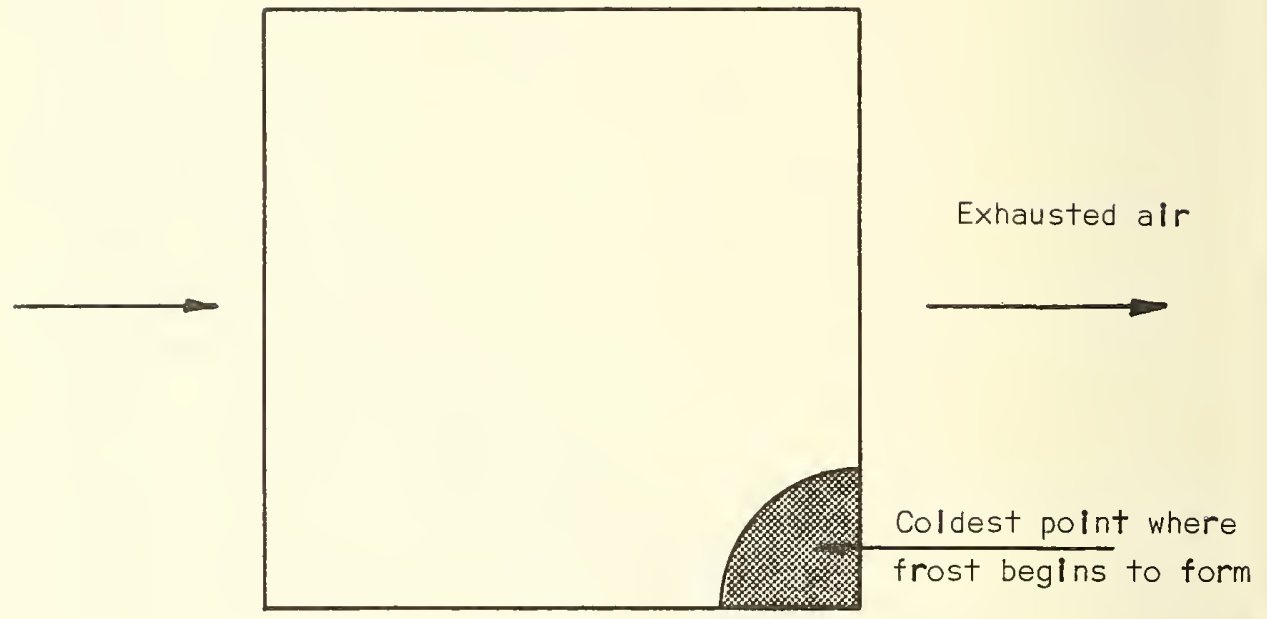

1

Figure 20. Point at which frost forms 
Pressure loss In Pascal

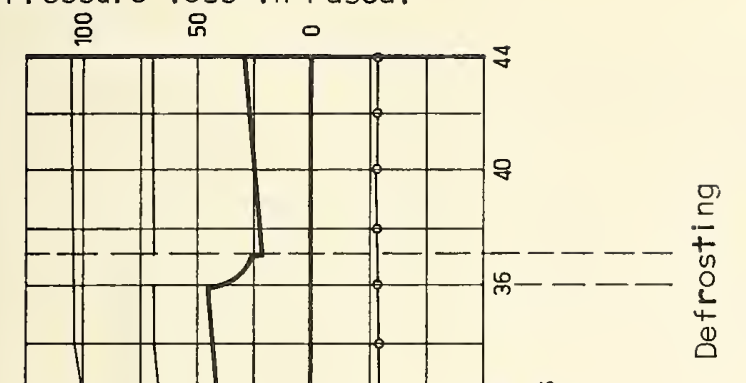

0
0
+0
$\frac{1}{7}$
0
$\frac{5}{x}$
0

$\stackrel{10}{+}$

$\begin{array}{lll}0 & 0 \\ & 0 & m \\ 0 & 0 & 1\end{array}$

$\begin{array}{llll}\frac{1}{0} & 0 & > & \frac{1}{0}\end{array}$

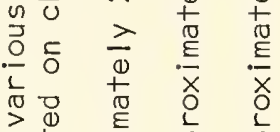

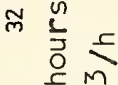

$\stackrel{\infty}{\simeq} \stackrel{\varepsilon}{0}$

$\stackrel{\oplus}{\stackrel{\Xi}{+}}+$

군

O

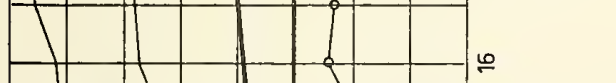

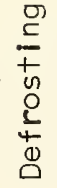

市 茂

ᄂ든 음 "

远

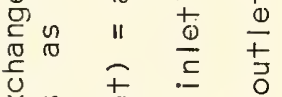

我
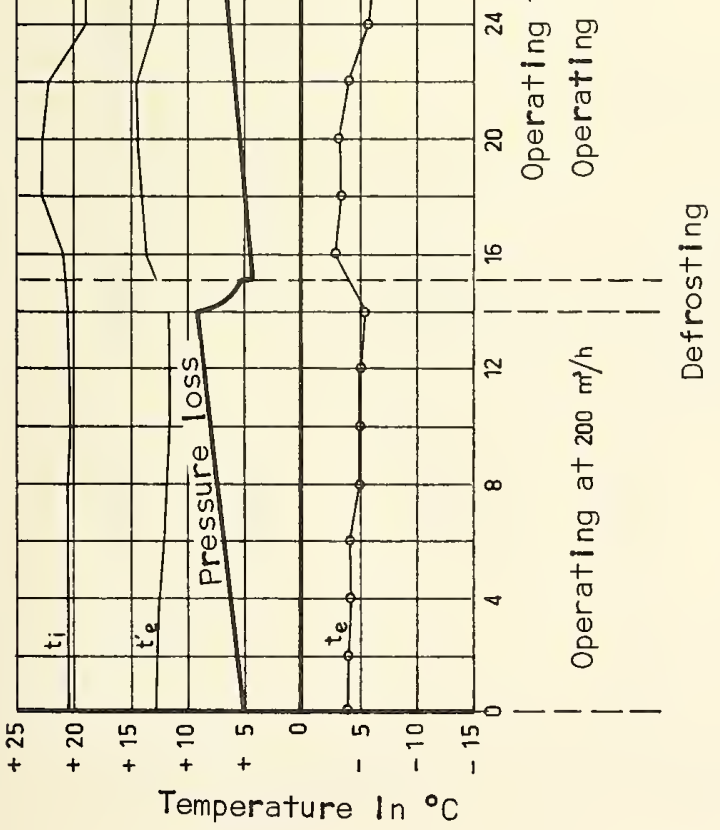

들

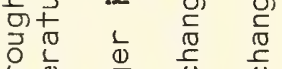

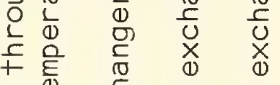

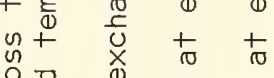

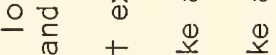

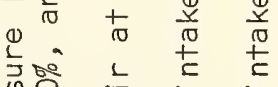

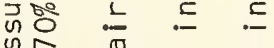

0 ᄂ ᄂ

등 प व

$\begin{array}{llll}+\pi & 1 & 1 & 1 \\ 0 & 0 & 0\end{array}$

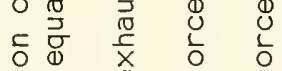

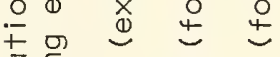

그에

耑号 $++^{0} 干^{0}$

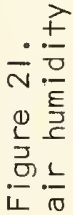


Pressure loss in Pascal

品只 员응

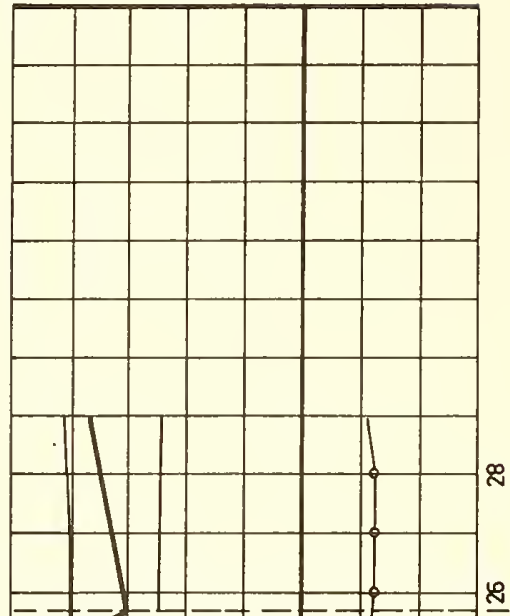

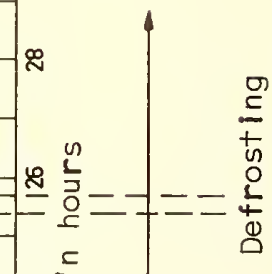

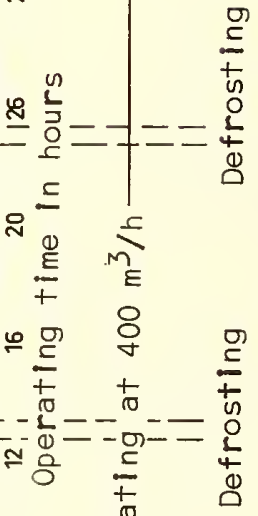
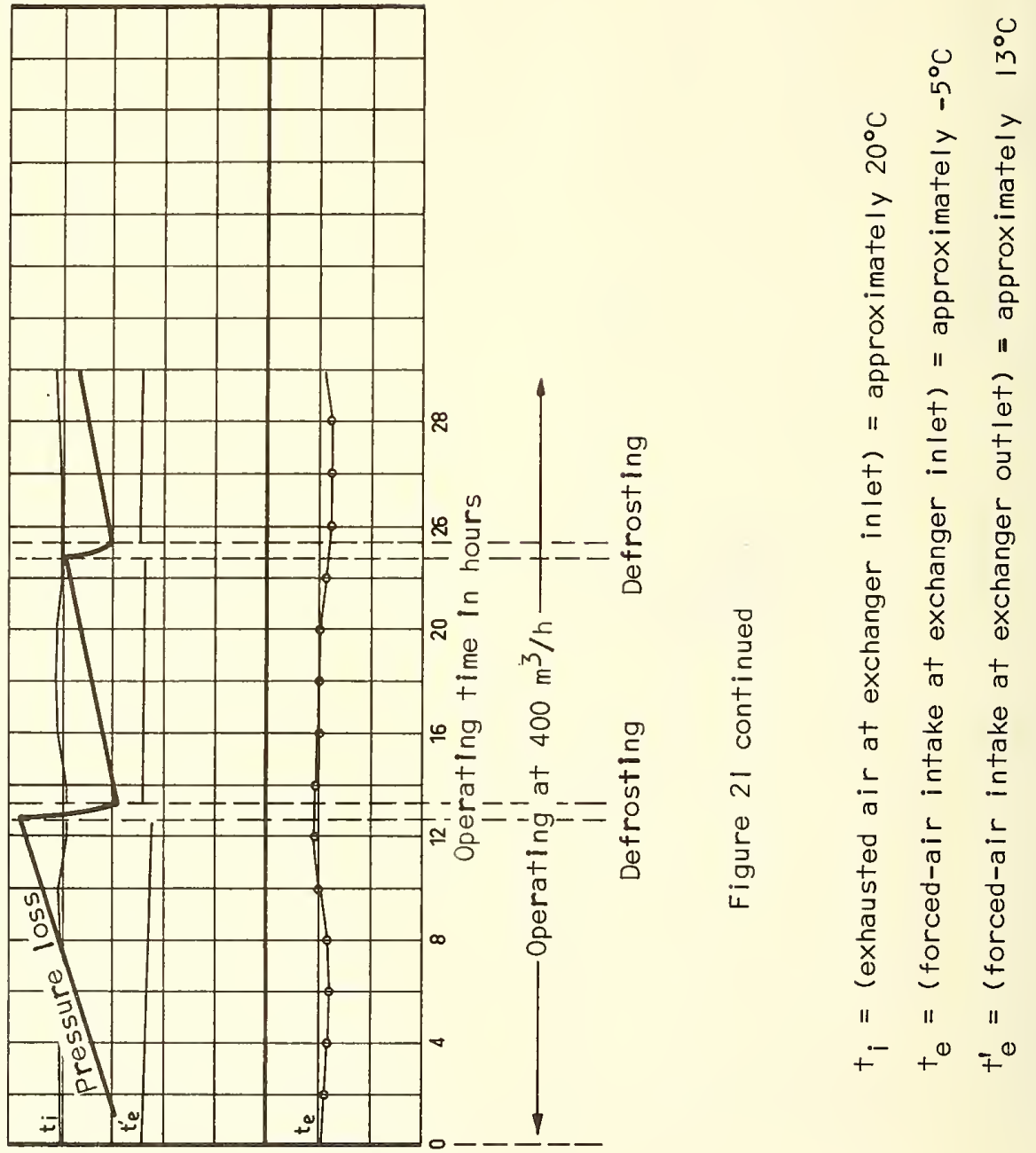

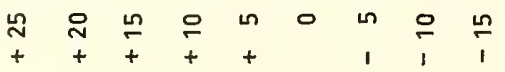

Temperature in ${ }^{\circ} \mathrm{C}$ 


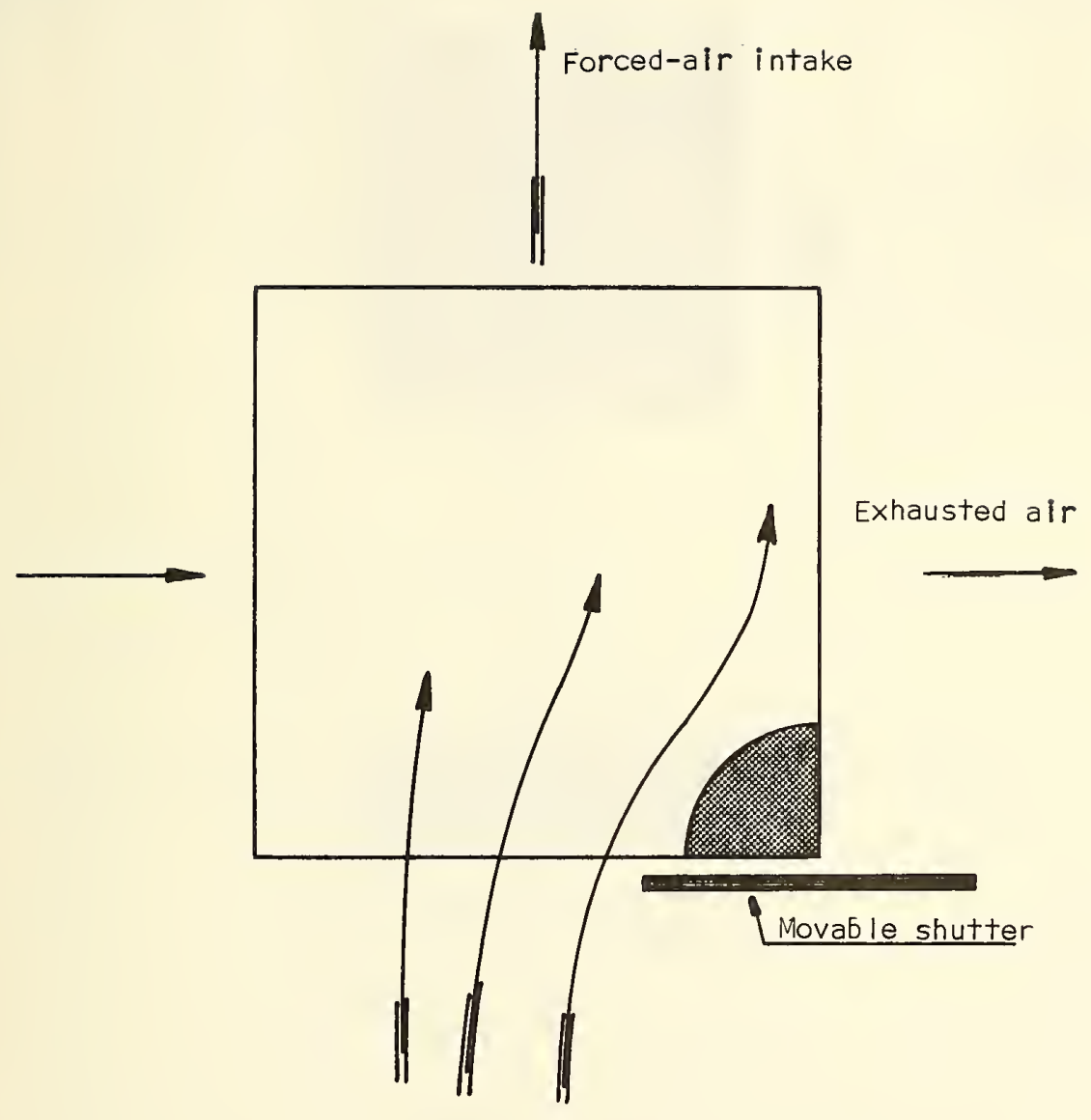

Figure 22. Diagram of the anti-frost solution considered. 


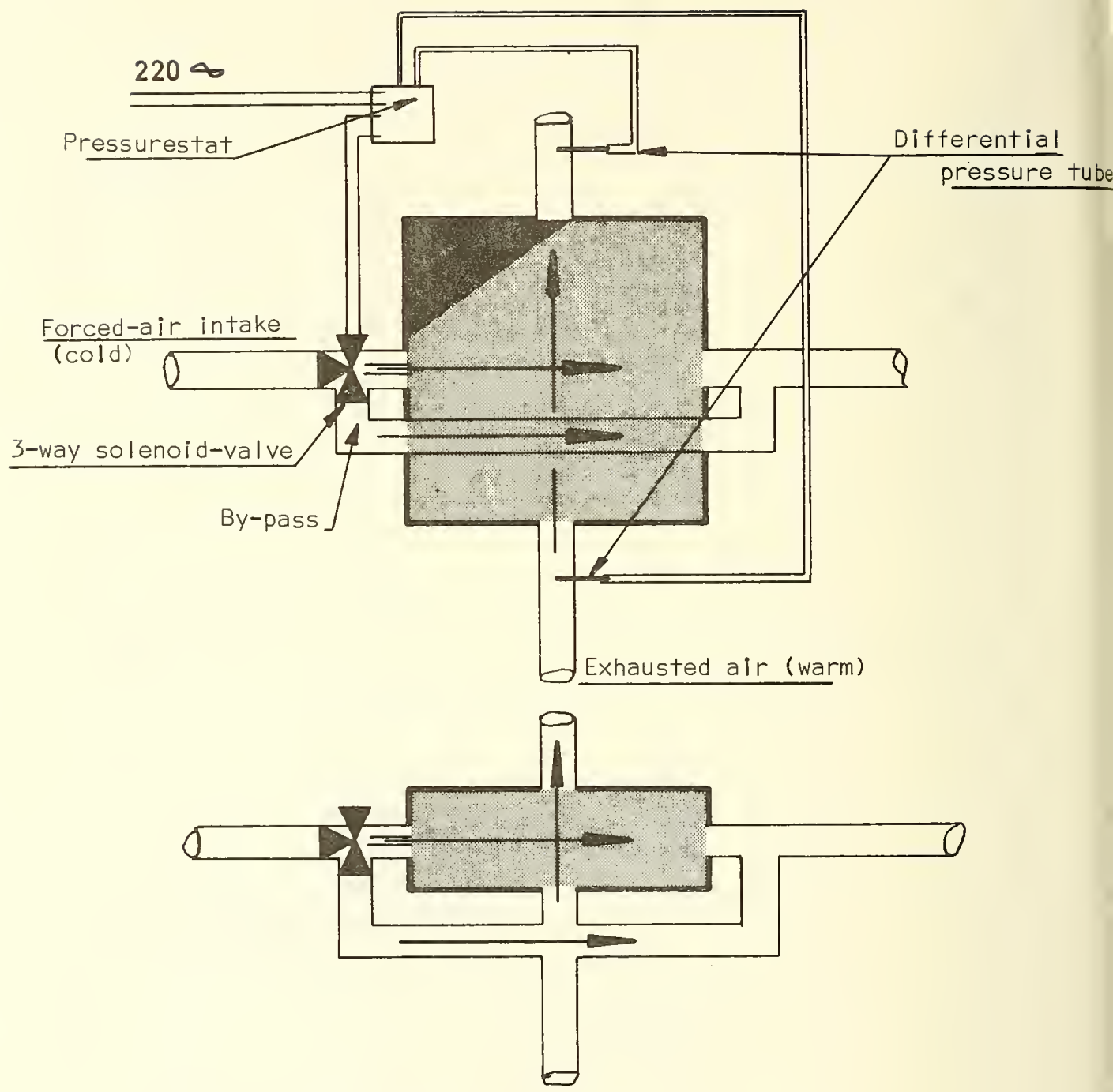

Figure 23. Automatic by-pass defrosting system

The principle of this system is as follows: The two desired pressure loss limits are set on the pressostat (Pressurestat). When frost forms, the pressure loss increases until it reaches the upper threshold set on the pressostat. The latter actuates the 3-way valve which diverts the forcedair intake into the by-pass circuit; thus, the exchanger is no longer cooled by the forced-air but is warmed by the exhausted air. This warm air defrosts the exchanger, thus lowering pressure loss down to the lower threshold limit set on the pressostat. The latter reactuates the 3-way valve which shuts off the by-pass and thus allows the forced-air intake to revert to its normal flow through the exchanger. 


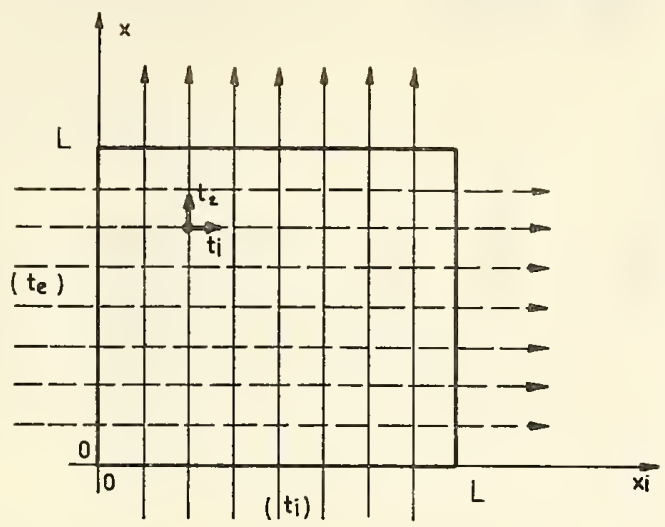

Figure 24.

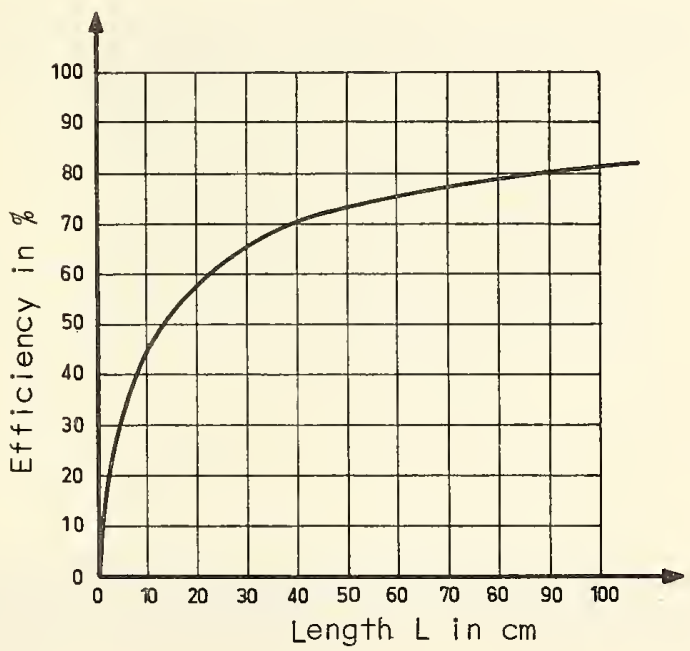

Figure 25. Variation of exchanger efficiency as a function of exchanger length $L$, with construction of plates and rates of flow such that $k_{j}=k_{2}=8 \cdot \mathrm{m}^{-1}$ and when number of plates is equal to 100. 

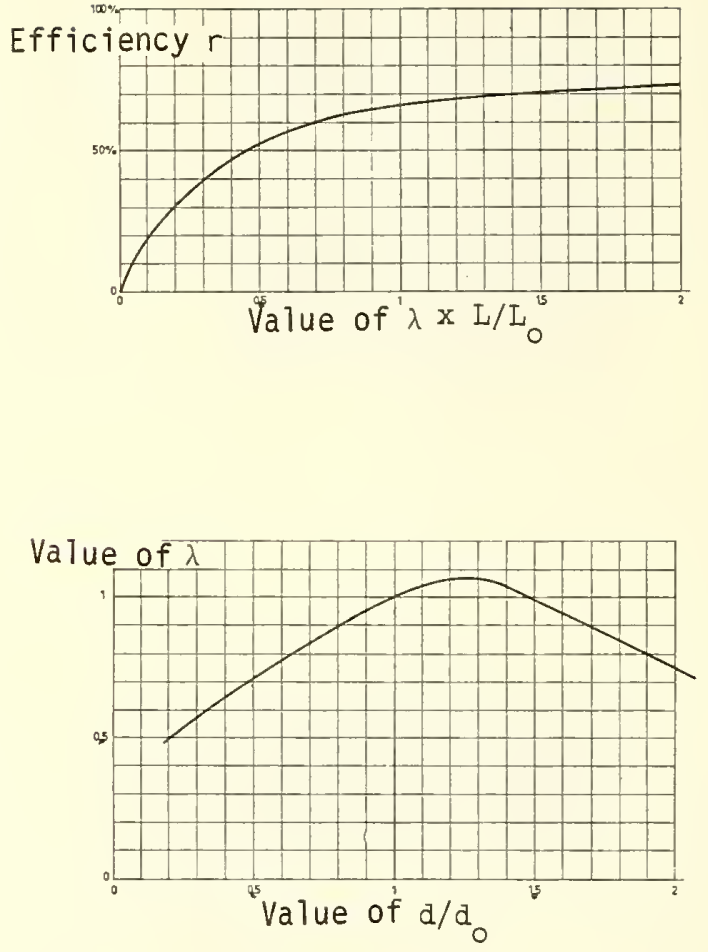

Figure 26. Variation of exchanger efficiency as function of its characteristics. 
FORM NBS-114A $\{1-71\}$

\begin{tabular}{|c|c|c|c|}
\hline $\begin{array}{l}\text { U.S. DEPT. OF COMM. } \\
\text { BIBLIOGRAPHIC DATA } \\
\text { SHEET }\end{array}$ & $\begin{array}{l}\text { 1. PUBLICATION OR REPORT NO. } \\
\text { NBS TN-710-5 }\end{array}$ & $\begin{array}{l}\text { 2. Gov't Accession } \\
\text { No. }\end{array}$ & 3. Recipient's Accession No. \\
\hline \multirow{2}{*}{\multicolumn{3}{|c|}{$\begin{array}{l}\text { 4. TITLE AND SUBTITLE } \\
\text { BUILDING RESEARCH TRANSLATION } \\
\text { USE OF AN AIR-TO-AIR HEAT EXCHANGER TO RECOVER HEAT FROM AIR } \\
\text { EXHAUSTED BY MECHANICAL VENTILATION }\end{array}$}} & $\begin{array}{c}\text { 5. Publication Date } \\
\text { July } 1972\end{array}$ \\
\hline & & & 6. Performiog Organization Code \\
\hline \multicolumn{3}{|l|}{$\begin{array}{l}\text { 7. AUTHOR(S) } \\
\text { P. Garrivier }\end{array}$} & 8. Performing Orgaoization \\
\hline \multirow{2}{*}{\multicolumn{3}{|c|}{$\begin{array}{l}\text { 9. PERFORMING ORGANIZATION NAME AND ADDRESS } \\
\text { NATIONAL BUREAU OF STANDARDS } \\
\text { DEPARTMENT OF COMMERCE } \\
\text { WASHINGTON, D.C. } 20234\end{array}$}} & $\begin{array}{l}\text { 10. Project/Task/Work Unit No. } \\
4213114\end{array}$ \\
\hline & & & 11. Contract/Grant No. \\
\hline \multirow{2}{*}{\multicolumn{3}{|c|}{ 12. Sponsoting Organization Name and Address }} & $\begin{array}{l}\text { 13. Type of Report \& Period } \\
\text { Covered } \\
\text { Final }\end{array}$ \\
\hline & & & 14. Sponsoring Agency Code \\
\hline
\end{tabular}

15. SUPPLEMENTARY NOTES

16. ABSTRACT (A 200-word or Iess factual summary of most significant information. If document includes a significant bibliography or literature survey, mention it here.)

When a building is equipped with a mechanical system which both exhausts and supplies outdoor air, it may be profitable to install a heat exchanger between the two circuits. The CSTB has perfected such an exchanger, which meets the two principal requirements of the problem: good efficiencies and elimination of the polluted air intake. A method of calculating the optimal dimensions of the exchanger has also been devised.

17. KEY WORDS (Aiphabetical order, separated by semicolons)

Exchanger dimensions; frost formation; heat exchanger; heating costs; mechanical systems; pollution; pressure loss; ventilation.

\begin{tabular}{|c|c|c|}
\hline $\begin{array}{l}\text { 18. AVAILABILITY STATEMENT } \\
\mathrm{X} \text { UNL IMITED. }\end{array}$ & $\begin{array}{l}\text { 19. SECURITY CLASS } \\
\text { (THIS REPORT) } \\
\text { UNCL ASSIF IED }\end{array}$ & $\begin{array}{c}\text { 21. NO. OF PAGES } \\
62\end{array}$ \\
\hline $\begin{array}{l}\square \text { FOR OFFICIAL DISTRIBUTION. DO NOT RELEASE } \\
\text { TO NTIS. }\end{array}$ & $\begin{array}{l}\text { 20. SECURITY CLASS } \\
\text { (THIS PAGE) } \\
\text { UNCL. ASSIFIED }\end{array}$ & $\begin{array}{r}\text { 22. Price } \\
\$ .60\end{array}$ \\
\hline
\end{tabular}



PERIODICALS

JOURNAL OF RESEARCH reports National Bureau of Standards research and development in physics, mathematics, and chemistry. Comprehensive scientific papers give complete details of the work, including laboratory data, experimental procedures, and theoretical and mathematical analyses. Illustrated with photographs, drawings, and charts. Includes listings of other NBS papers as issued.

Published in two sections, available separately:

\section{- Physics and Chemistry}

Papers of interest primarily to scientists working in these fields. This section covers a broad range of physical and chemical research, with major emphasis on standards of physical measurement, fundamental constants, and properties of matter. Issued six times a year. Annual subscription: Domestic, $\$ 9.50 ; \$ 2.25$ additional for foreign mailing.

\section{- Mathematical Sciences}

Studies and compilations designed mainly for the mathematician and theoretical physicist. Topics in mathematical statistics, theory of experiment design, numerical analysis, theoretical physics and chemistry, logical design and programming of computers and computer systems. Short numerical tables. Issued quarterly. Annual subscription: Domestic, \$5.00; $\$ 1.25$ additional for foreign mailing.

\section{TECHNICAL NEWS BULLETIN}

The best single source of information concerning the Bureau's measurement, research, developmental, cooperative, and publication activities, this monthly publication is designed for the industry-oriented individual whose daily work involves intimate contact with science and technology-for engineers, chemists, physicists, research managers, product-development managers, and company executives. Includes listing of all NBS papers as issued. Annual subscription: Domestic, $\$ 3.00 ; \$ 1.00$ additional for foreign mailing.

\section{Bibliographic Subscription Services}

The following current-awareness and literaturesurvey bibliographies are issued periodically by the Bureau: Cryogenic Data Center Current Awareness Service (weekly), Liquefied Natural Gas (quarterly), Superconducting Devices and Materials (quarterly), and Electromagnetic Metrology Current Awareness Service (monthly). Available only from NBS Boulder Laboratories. Ordering and cost information may be obtained from the Program Information Office, National Bureau of Standards, Boulder, Colorado 80302 .

\section{HONPERIODICALS}

Applied Mathematics Series. Mathematical tables, manuals, and studies.

Building Science Series. Research results, test methods, and performance criteria of building materials, components, systems, and structures.

Handbooks. Recommended codes of engineering and industrial practice (including safety codes) developed in cooperation with interested industries, professional organizations, and regulatory bodies.

Special Publications. Proceedings of NBS conferences, bibliographies, annual reports, wall charts, pamphlets, etc.

Monographs. Major contributions to the technical literature on various subjects related to the Bureau's scientific and technical activities.

\section{National Standard Reference Data Series.} NSRDS provides quantitative data on the physical and chemical properties of materials, compiled from the world's literature and critically evaluated.

Product Standards. Provide requirements for sizes, types, quality, and methods for testing various industrial products. These standards are developed cooperatively with interested Government and industry groups and provide the basis for common understanding of product characteristics for both buyers and sellers. Their use is voluntary.

Technical Notes. This series consists of communications and reports (covering both other-agency and NBS-sponsored work) of limited or transitory interest.

Federal Information Processing Standards Publications. This series is the official publication within the Federal Government for information on standards adopted and promulgated under the Public Law 89-306, and Bureau of the Budget Circular A-86 entitled, Standardization of Data Elements and Codes in Data Systems.

Consumer Information Series. Practical information, based on NBS research and experience, covering areas of interest to the consumer. Easily understandable language and illustrations provide useful background knowledge for shopping in today's technological marketplace.

\section{CATALOGS OF NBS PUBLICATIONS}

NBS Special Publication 305, Publications of the NBS. 1966-1967. When ordering, include Catalog No. C13.10:305. Price $\$ 2.00 ; 50$ cents additional for foreign mailing.

NBS Special Publication 305, Supplement 1, Publications of the NBS, 1968-1969. When ordering, include Catalog No. C13.10:305/Suppl. 1. Price $\$ 4.50 ; \$ 1.25$ additional for foreign mailing.

NBS Special Publication 305, Supplement 2, Publications of the NBS, 1970. When ordering, include Catalog No. C13.10:305/Suppl. 2. Price $\$ 3.25 ; 85$ cents additional for foreign mailing. 
U.S. DEPARTMENT OF COMMERCE

National Bureau of Standards

Washington, D.C. 20234

POSTAGE ANO FEES PAIO U.S. OEPARTMENT OF COMMERCE 215

OFFICIAL GUSINESS

Penalty for Private Use, \$300 